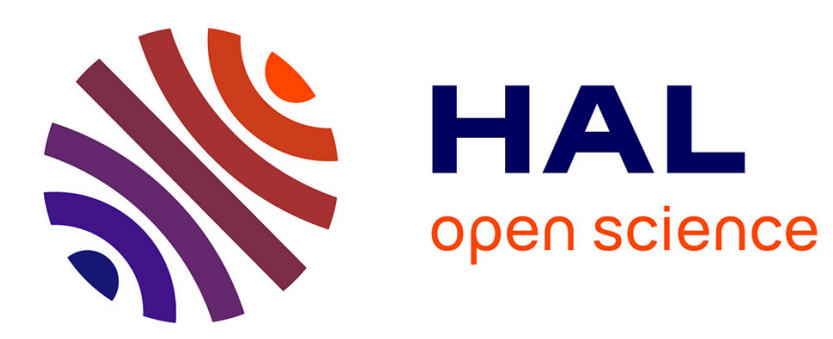

\title{
Corvids exhibit dynamic risk assessment during escape
}

Kunter Tätte, Anders Moller, Raivo Mänd

\section{To cite this version:}

Kunter Tätte, Anders Moller, Raivo Mänd. Corvids exhibit dynamic risk assessment during escape. Behavioural Processes, 2019. hal-03024827

\section{HAL Id: hal-03024827 \\ https://cnrs.hal.science/hal-03024827}

Submitted on 26 Nov 2020

HAL is a multi-disciplinary open access archive for the deposit and dissemination of scientific research documents, whether they are published or not. The documents may come from teaching and research institutions in France or abroad, or from public or private research centers.
L'archive ouverte pluridisciplinaire HAL, est destinée au dépôt et à la diffusion de documents scientifiques de niveau recherche, publiés ou non, émanant des établissements d'enseignement et de recherche français ou étrangers, des laboratoires publics ou privés. 


\section{Manuscript Details}

\section{Manuscript number}

Title

Article type
BEPROC_2019_251_R2

Corvids exhibit dynamic risk assessment during escape

Research Paper

\section{Abstract}

It is widely accepted that stationary prey are able to carefully assess the risk levels associated with an approaching predator to make informative decisions on when to escape. However, little is known about subsequent decisionmaking process. We set out to compare whether escape durations of three species of corvids differ depending on how a human observer (in the role of a predator) behaves after the escape has begun. When birds were being followed during escape, escape durations were the longest, escape trajectory was modified the most during escape, and a larger proportion of individuals changed from terrestrial to aerial escape strategy compared to observations where birds were not followed. Mean horizontal escape angle of ca $120^{\circ}$ was also a potential indication that monitoring the threat is taken into account when deciding on the escape trajectory. While there were some differences between the behaviour of these three closely related species, the general patterns supported the notion that birds dynamically assess risk during escape to find an optimal balance between getting caught and spending too much time and energy on escaping. Further research using different predator-prey combinations or making comparisons between habitats could help understand the generality of our results.

\section{Keywords}

Corresponding Author

Corresponding Author's Institution

Order of Authors

Suggested reviewers antipredator behaviour; birds; Corvidae; escape behaviour; escape duration; risk assessment

Kunter Tätte

University of Tartu

Kunter Tätte, Anders Moller, Raivo Mänd

Nadine Kalb, Kenta Uchida, Yves Bötsch, Jose Nunes 


\section{Submission Files Included in this PDF}

File Name [File Type]

Cover letter - with title page_26.11.2019.docx [Cover Letter]

Response to Reviewers 26.11.2019.docx [Response to Reviewers]

HIGHLIGHTS 25.11.2019 -clean.docx [Highlights]

DRA Abstract 15.10.2019.docx [Abstract]

DRA Manuscript 25.11.2019_CLEAN.docx [Manuscript File]

Fig. 1. Ydenberg Dill graphical model with addition from Blumstein.pdf [Figure]

Fig. 2. Schematic illustration of different approach types_v3.pdf [Figure]

Fig. 3. Escape duration - Approach type $x$ Species.pdf [Figure]

Fig. 4. Escape duration - Approach type x Escape type.pdf [Figure]

Fig. 5. Initial escapes angles of Eurasian jackdaw, hooded crow, rook.pdf [Figure]

Fig. 6. Change in escape angle - Approach type x Escape type.pdf [Figure]

Fig. A1.jpg [Figure]

Fig. A2. Escape duration x Distance fled by Escape type_new_visuals.pdf [Figure]

Fig. A3. Escape duration x Escape angle by Species.pdf [Figure]

Fig. A4. Starting distance $x$ Escape duration $x$ Species.pdf [Figure]

Fig. A5. Escape duration x FID-phi by Approach type.pdf [Figure]

Author statement.docx [Author Statement]

\section{Submission Files Not Included in this PDF}

File Name [File Type]

Electronic Supplementary Table S1.xlsx [Table]

Electronic Supplementary Table S2.xlsx [Table]

Electronic Supplementary Table S3.xlsx [Table]

Electronic Supplementary Table S4.xlsx [Table]

To view all the submission files, including those not included in the PDF, click on the manuscript title on your EVISE Homepage, then click 'Download zip file'. 


\section{Cover letter}

Kunter Tätte

University of Tartu

Vanemuise 46, EE-51014 Tartu, Estonia

Tel: +3725665 1177

kunter.tatte@gmail.com

November 26, 2019

Dear Prof. Bolhuis,

We have now addressed all the minor comments by Reviewer 2. In addition, we did some small updates to Fig. A2 and its legend to improve readability.

I have also added the title page of the manuscript to the second page of this cover

letter.

Yours sincerely,

Kunter Tätte 
Corvids exhibit dynamic risk assessment during escape

Kunter Tätte ${ }^{1^{*}}$, Anders Pape Møller ${ }^{2}$, Raivo Mänd ${ }^{1}$

${ }^{1}$ University of Tartu, Institute of Ecology and Earth Sciences, Department of Zoology, Estonia

2 Ecologie Systématique Evolution, Université Paris-Sud, CNRS, AgroParisTech, Université Saclay, France; Ministry of Education Key Laboratory for Biodiversity Science and Ecological Engineering, College of Life Sciences, Beijing Normal University, Beijing 100875, China

Abbreviated title: Risk assessment during escape

Declarations of interest: none.

${ }^{*}$ Correspondence:

Kunter Tätte

e-mail: kunter.tatte@gmail.com

Tel.: +37256651177

Addr.: Vanemuise 46, EE-51014 Tartu, Estonia 


\section{-Reviewer 2}

The authors have done an excellent job addressing the comments on their initial submission. The statistical approach is greatly improved and my other main concerns are satisfied.

Response: Thank you!

A few minor comments:

-Highlights: Please add a first point with some idea of the hypothesis tested. The conclusion here could also benefit from some mention of why that is relevant.

Response: Great suggestion! Added: "This study examined whether birds adjust escape plans while fleeing".

L44: I agree that FID tests are "immensely popular", but I'm not sure about that particular description here - "commonly used", perhaps?

Response: Changed to "commonly used".

L60-61: Escape duration should be the time elapsed between flight initiation and return to the original position (or, perhaps, resuming pre-stim activities). Flight time would be the variable related to distance fled. This distinction seems to be present in the Methods \& Results.

Response: We must politely disagree on this suggestion. While "flight time" has indeed been used in Collop et al. (2016) and Holmern et al. (2016, Behav. Ecol.) to describe antipredator escape responses, it is commonly used to describe any aerial movement in birds, bats, and flying insects (as shown by searches on ISI Web of Knowledge). "Escape duration", however, should clearly indicate that this is the time elapsed during fleeing and that it can include terrestrial escapes as well. For example, a reviewer in another journal once asked us to change the phrase "takes flight" because he/she thought that it was a term related only to aerial escapes. We are not aware of studies that use "escape duration" as a measure of escape that includes the time it takes for the animal to return to the original position, as you suggested. Returning to the original location is usually not considered a part of the predatory sequence (e.g. Endler 1991).

L61: Sentence fragment - can delete or incorporate into previous sentence.

Response: Deleted 
L85-87: It would be helpful to include the directions of these FID differences from Cooper (e.g. slow approach-small FID, fast approach-large FID?) to give some context to your question \& results.

Response: We have now specified that slow approaches result in short FID and fast approaches in a long FID (line 86).

L91: The two commas here are unnecessary.

Response: Removed the commas.

L91-97: This is pedantic and I apologize, but "studies" appears 4 times in this section (plus L104). Suggest an initial conditional, and then just discuss the findings.

Response: Now that you have pointed it out, it really does sound bad. We have changed the phrasing, so that "studies" is used only once in the beginning.

L107-108: This statement is very strong - such that I think a thorough, systematic review of the literature (including a complete list of databases, search terms, returned items, rejected items, criteria for rejection, etc.) is required to make it. Please tone down the absoluteness.

Response: Indeed, we may have been too hasty in our judgement. There might be studies out there that we have not stumbled upon (due to a different choice of keywords, for example). We have deleted the first two sentences of this paragraph.

L150: Escape AT greater distances, or escape TO greater distances?

Response: We have now made it clear by writing out: "larger species tend to have longer distance fled" (line 144).

L151-152: This sentence is unwieldy - just to say that "species" was included as a categorical factor in the analysis.

Response: We simplified the sentence a bit. Now it states: "We also examined whether there are any interspecific differences in how risk is assessed".

L206: The two commas in this sentence are unnecessary.

Response: Deleted the commas.

L355: Which dependent variable?

Response: Now it says "escape angle" instead of "dependent variable". 
L518: "outsmart" is rather subjective.

Response: Ok, removed. "Outmanoeuvre" should be enough to deliver the message. 


\section{HIGHLIGHTS}

- This study examined whether birds adjust escape plans while fleeing

- Following corvids during their escape increased escape duration

- Corvids that were followed made larger turns during escape

- Corvids switched from terrestrial escape to aerial escape more often when followed

- Results suggest that prey continue to monitor predators during escape 


\section{ABSTRACT}

2 It is widely accepted that stationary prey are able to carefully assess the risk levels

3 associated with an approaching predator to make informative decisions on when to

4 escape. However, little is known about subsequent decision-making process. We set

5 out to compare whether escape durations of three species of corvids differ

6 depending on how a human observer (in the role of a predator) behaves after the

7 escape has begun. When birds were being followed during escape, escape

8 durations were the longest, escape trajectory was modified the most during escape,

9 and a larger proportion of individuals changed from terrestrial to aerial escape

10 strategy compared to observations where birds were not followed. Mean horizontal

11 escape angle of ca $120^{\circ}$ was also a potential indication that monitoring the threat is

12 taken into account when deciding on the escape trajectory. While there were some

13 differences between the behaviour of these three closely related species, the general

14 patterns supported the notion that birds dynamically assess risk during escape to

15 find an optimal balance between getting caught and spending too much time and

16 energy on escaping. Further research using different predator-prey combinations or

17 making comparisons between habitats could help understand the generality of our 18 results. 


\section{INTRODUCTION}

21 A large variety of antipredator adaptations exist in the animal kingdom, but one of the most common is escape, considering that even morphologically or chemically well protected species still often turn to escape when encountering a predator (Hatle et al. 2001; Polo-Cavia et al. 2008). The safest way to avoid being injured or depredated is to distance oneself from predators. However, escape can be costly if it interrupts a fitness enhancing activity, such as foraging, courting, or defending its territory, and escape itself can be costly in energetic terms (Ydenberg \& Dill 1986). Therefore, it is necessary for prey to correctly assess the degree of predation risk posed by a predator or other threatening stimulus to avoid unnecessary costs (Ydenberg \& Dill 1986). In other words, while an underestimation of risk could be lethal for prey, an overestimation of risk would be costly as well - especially if the prey reveals itself to a predator that had no prior intent of attack (Broom \& Ruxton 2005).

The first and most recognized economic model of escape behaviour was a simple graph by Ydenberg \& Dill (1986), illustrating the changes in the costs of fleeing and remaining of a stationary prey when approached by a predator. The model predicted that the optimal distance for escape would be when the cost of fleeing is equal to the cost of remaining. This model has been updated by Blumstein (2003) to distinguish the risk assessment zone (Zone II in Fig. 1) from the zone where risk is not assessed due to overly long distance between prey and predator (Zone III in Fig. 1), and from the zone where escape is immediate due to short distance (Zone I in Fig. 1). These models have been made to predict flight initiation distance (FID) - the remaining distance between prey and 
44 predator at the moment of escape. FID has become a commonly used measure of fearfulness and has been used for various taxa to test hypotheses about decisions made under threat of predation (Cooper \& Blumstein 2015). Most studies that make use of FID use a human observer as an approaching predator (Stankowich \& Blumstein 2005) because humans and human-caused disturbances can also be considered a form of predation risk (Frid \& Dill 2002). FID is a consistently repeatable personality trait (Carter et al. 2010; Holtmann et al. 2017; López \& Martín 2015), but it is also affected by extrinsic factors, such as the speed, size, and directness of an approaching predator (Stankowich \& Blumstein 2005). Moreover, FID is negatively correlated with the density of pedestrians (Mikula, 2014; Stankowich \& Blumstein 2005), which is likely to be a result of both habituation and risk allocation (Rodriguez-Prieto et al. 2008b). Population level differences in FID, such as urban boldness, can also be explained by microevolutionary changes (Møller 2008) or phenotypic sorting (Holtmann et al. 2017).

Another important parameter of escape is distance fled (Tätte et al. 2018), or when measured in time units - escape duration or flight time (Collop et al. 2006).. Distance fled has received little attention in escape models (Cooper \& Blumstein 2015, p. 57) and is often regretfully neglected when the costs of escape are discussed (Tätte et al. 2018). Cooper \& Pérez-Mellado (2004) have suggested that distance fled could be similarly modelled as FID, with one slope predicting risk of predation, and the other predicting cost of leaving a resource (as in Fig. 1). However, it is unclear whether distance fled is decided upon the moment of escape, or whether prey continuously, during escape, assess the 
risk of predation and other costs of escape to decide on the final destination. In addition, the so-called zigzagging escape during chase (characterized by frequent turns) is typically attributed to increasing unpredictability of escape

71 (Domenici \& Ruxton 2015, p. 213), and not seen as a series of informed

72 corrections to escape trajectory. The question of dynamic risk assessment

73 (DRA) has been briefly discussed in relation to FID (Cooper 1998; Cooper

74 2006a; Bateman \& Fleming 2014), time spent in refuge (Martín \& López 2005),

75 and distance fled (Bateman \& Fleming 2014; Collier \& Hogdson 2017), but there 76 seems to be ambiguity about what is dynamic assessment and what is not.

77 Cooper (1998) was possibly the first to point out that the economic model of escape (Ydenberg \& Dill 1986) does not account for rapidly changing risk curves, after studying how lizards react to sudden turns by an approaching human. The first study to have purposefully tried to demonstrate DRA in escape behaviour was by Cooper (2006a), who examined how lizards change their FID 82 in relation to the speed of an approaching predator. More specifically, Cooper 83 (2006a) tested whether switching his walking speed from slow to fast, and from fast to slow during approach have a different effect on FID from not changing speed midway. It was evident that slow and fast-slow speeds resulted in a highly similar short FID, and fast and slow-fast speeds had a similar long FID.

87 Cooper (2006a) concluded that FID depends only on the final approach speed, and that this was strong evidence for his hypothesis that prey continuously assess the predation risk when encountering a predator.

90 Other studies that have attempted to demonstrate DRA in escape have been

91 done by making successive approaches towards prey after its escape. Bateman 
92 \& Fleming (2014) and Collier \& Hogdson (2017) found that grasshoppers

93 change their escape strategies over successive approaches depending on the

94 perceived risk of predation. While it was shown that risk of predation is quickly

95 recalculated, it was unclear whether risk was assessed in real time during

96 escape or just before each escape. If even a momentary delay can be enough

97 to make new accurate risk assessments, as shown in Lind et al. (2002), then a

98 methodology using repeat approaches cannot be regarded as a continuous

99 pursuit. That is, new escape decisions could still have been made before each

100 escape. The cost of remaining could have increased each time because of the

101 heightened perception of predation risk from previous escape attempts.

102 Behaviour in these experiments on grasshoppers changed dynamically, but

103 possibly not in the way originally hypothesized by Cooper $(1998,2006 a)$.

104 While there is plenty of evidence to suggest that prey do indeed monitor 105 approaching predators before initiating flight (Stankowich \& Blumstein 2005;

106 Cooper \& Blumstein 2015), the extent to which they monitor while fleeing is less 107 clear. For example, some lizards stop shortly after escape, and subsequently 108 turn their heads to the side to monitor and assess risk (Cooper 2008). While 109 some species, e.g. the Eurasian woodcock (Scolopax rusticola), do have a $360^{\circ}$ 110 view of their surroundings (Martin 1994), most birds tend to have a blind area at 111 the back of their head (Martin 2007), including corvids (Fernández-Juricic et al. 112 2010). Furthermore, visual acuity varies in different parts of the visual field, 113 forcing birds to move their heads or eyes when monitoring their surroundings 114 (Fernández-Juricic 2012). Thus, DRA during escape would put requirements on 115 the movement of the head, or on the escape trajectory. Indeed, escape angles 
116 that allow continuous tracking of predator during escape are common in several

117 taxa (Domenici \& Ruxton 2015). However, birds, though poorly studied

118 regarding horizontal escape trajectories, have been characterized by having two

119 peaks: $180^{\circ}$ to maximize distance from the predator (sometimes followed by a

120 turn towards the predator to fly over it), and $90^{\circ}$ for rapid evasion from

121 predator's line of attack (Domenici et al. 2011).

122 The goal of the current study was to test whether escape by birds change in a 123 way consistent with DRA when escaping from predators - that is, to study the 124 ability to adjust escape plans in real time according to the actions of predators.

125 For that, we made three different types of approaches: "halt" - the potential 126 predator (human) comes to a halt when the bird initiates escape; "forward" 127 approach is continued in a straight line after escape begins; "chase" - the bird is 128 chased during escape (Fig. 2, see Materials and methods for details). Perceived 129 risk of predation was assessed by measuring escape duration. We predicted 130 that the time spent on escape will be the shortest in the case of approach type 131 "halt", intermediate with type "forward", and the longest with type "chase". If prey 132 would not continue risk assessment during escape, then there would be no 133 significant variation among different approach types as the destination would be 134 pre-fixed. In addition, we set out to further examine the patterns of escape 135 durations by including potential covariates and factors - such as FID, escape 136 angles, species identity, and escape strategy (see Materials and methods) - in 137 a linear mixed-effects analysis. Furthermore, we took interest in finding potential 138 predictors of initial escape angle and angular change during escape as these 139 variables could provide additional explanations for the variation in escape 
140 routes. Three relatively similar species of corvids were used in the study: the

141 hooded crow (Corvus cornix), the rook (Corvus frugilegus), and the Eurasian

142 jackdaw (Coloeus monedula). We selected corvids because their high cognitive

143 abilities (Cramp et al. 2004; Emery \& Clayton 2004) should favour DRA, and

144 larger species tend to have longer distance fled (Tätte et al. 2018), which gives

145 them more time to assess risk. We also examined whether there are any

146 interspecific differences in how risk is assessed. Studying how animals react to

147 different stimuli under threat of predation helps to understand how human-

148 caused disturbances could affect the well-being of wild animals (Frid \& Dill 149 2002).

150 2. MATERIAL AND METHODS

\section{$151 \quad 2.1$ Study system}

152 The study was conducted in two major Estonian cities, Tartu $\left(58^{\circ} 23^{\prime} \mathrm{N} 26^{\circ} 43^{\prime} \mathrm{E}\right)$

153 and Tallinn $\left(59^{\circ} 26^{\prime} \mathrm{N} 24^{\circ} 44^{\prime} \mathrm{E}\right)$ from May to July, 2018. We set out to collect data

154 until we had at least 90 behavioural observations of each corvid species. The

155 final data set consisted of 90 hooded crows, 108 rooks, and 126 Eurasian

156 jackdaws. Potential resampling of individuals was minimized by not visiting the

157 same locations (e.g. parks, streets) more than once. Observations were

158 conducted between 8 AM and 5 PM under similar weather conditions (no

159 precipitation, wind speed less than $6 \mathrm{~m} / \mathrm{s}$, temperature $11-22^{\circ} \mathrm{C}$ ).

160 The hooded crow, the rook, and the Eurasian jackdaw are common species in

161 Estonian cultural landscapes, but have often been persecuted by humans (Elts

162 et al. 2018). The hooded crow and the rook are similar in size (44-47 cm in

163 length), while the Eurasian jackdaw is $75 \%$ smaller than the two $(33-34 \mathrm{~cm})$ 
164 (Cramp et al. 2004). Smaller birds usually have a shorter FID (Blumstein 2006)

165 and distance fled (Tätte et al. 2018), and that is the case for the Eurasian

166 jackdaw as well, compared with the other two species (Livezey et al. 2016;

167 Tätte et al. 2018). The Eurasian jackdaw and the rook are typically colonial,

168 while the hooded crow is territorial (Cramp et al. 2004). All three species almost

169 wholly forage on the ground and can be seen flocked together when foraging or

170 roosting (Cramp et al. 2004). Picking food from the surface is the most frequent

171 foraging behaviour for the Eurasian jackdaw and the hooded crow, while deep

172 probing the soil is the most frequent for the rook (Waite 1984).

\section{$173 \quad 2.2$ Starting distance}

174 Upon finding a corvid on the ground, we measured the starting distance (i.e. the

175 distance between the observer and the bird) with Laser Rangefinder

176 PROSTAFF 3i (Nikon Vision Co., Ltd., Tokyo, Japan; measurement range 7.3-

$177590 \mathrm{~m}$, accuracy $0.1 \mathrm{~m}$ ). We avoided starting distances that were considerably

178 shorter than $30 \mathrm{~m}$ because with short starting distances, there is a risk that the

179 bird is already in the zone of maximum risk where prey immediately escape

180 when spotting a predator (Fig. 1; Blumstein 2003). Furthermore, unpublished

181 data from our previous studies indicates that the three selected species of

182 corvids very rarely have FIDs longer than $24 \mathrm{~m}$ in Estonian urban areas (6

183 observations out of 486). In the present study, starting distances ranged from

$18428.0 \mathrm{~m}$ to $59.4 \mathrm{~m}$ and the median was $33.7 \mathrm{~m} \mathrm{(1}{ }^{\text {st }}$ quartile $31.3,3^{\text {rd }}$ quartile

185 37.4). We also recorded the activity of the focal bird. Out of the total 323

186 observations in this study, $278(86.1 \%)$ focal birds were foraging, $27(8.4 \%)$ 
187 were resting, $16(5 \%)$ were eating, $1(0.3 \%)$ was grooming itself, and $1(0.3 \%)$ 188 was vocalizing.

\subsection{Approach type}

190 Next, we approached the focal bird at a normal walking speed (about $1.3 \mathrm{~m} / \mathrm{s}$ ),

191 but the termination of approach depended on the approach type. We

192 approached birds in three ways: (I) approach until the bird initiated escape

193 (defined as "halt"); (II) approach was continued in a straight line after escape

194 begins (regardless of the escape direction of the bird) until the bird stops or the

195 observer reaches the initial location of the bird (defined as "forward"); and (III)

196 the bird was followed during escape until it stopped (defined as "chase") (Fig.

197 2). For approach type "forward", the initial location of the bird was selected as

198 the termination point because often it is not possible to continue walking

199 indefinitely beyond the initial spot due to obstacles such as trees, fences or

200 buildings. The order in which approach types were executed followed a

201 continuous loop, i.e. "halt"-“forward"-“chase"-"halt"-"forward"-“chase" etc.

202 Eliciting an escape response causes only a brief disturbance for urban birds

203 that should not significantly differ from the daily disturbance involuntarily caused

204 by pedestrians.

$205 \quad 2.4$ Flock size

206 Flock size was estimated as the number of individual corvids in a $15 \mathrm{~m}$ radius of

207 the focal bird (chosen as the one closest to the observer), similarly to e.g. Guay

208 et al. (2013), Samia et al. (2017) and Tätte et al. (2018). Other individuals from

209 that flock were not experimentally approached. However, on some occasions,

210 when flocks were few and large (extending over the $15 \mathrm{~m}$ radius), multiple 
211 individuals from these extended flocks were approached. The latter was done

212 only when it was clear that the second individual showed no visible alert

213 behaviour (i.e. head-up posture) after the first one had escaped, and when

214 there was at least 30 m of starting distance to the second individual. In addition,

215 the observer waited at least two minutes before initiating the new approach to

216 further minimize potential carryover effects.

\section{$217 \quad 2.5$ Escape duration and its predictors}

218 We noted whether escape was terrestrial, aerial, or both (i.e. the bird switched

219 from terrestrial to aerial escape strategy while fleeing). However, in the

220 statistical models we used a binary escape strategy where terrestrial strategy

221 also includes the strategy "both", because there were too few observations from

222 the category "both" to make more precise models. Escape duration was

223 measured with a stopwatch from the moment escape was initiated until the bird

224 stopped (even if temporarily) with centisecond (cs) precision. If a bird escaped

225 out of sight (13.3\% of cases: $N=15$ for approach type "halt", $N=14$ for type

226 "forward", and $N=14$ for type "chase"), counting immediately stopped. Each

227 escape trajectory was drawn onto a circle by visual estimation to measure initial

228 and final escape angle in relation to the observer. Later, the difference between

229 initial and final escape angles was defined as change in escape angle.

230 Whenever possible (93.2\% of cases), distance fled was linearly measured in

231 addition to escape duration, as in Tätte et al. (2018), but we preferred to use

232 escape duration as the dependent variable because it is a more precise

233 characteristic when dealing with non-linear escape paths (e.g. zigzag

234 movement). Furthermore, height and type of the chosen refuge (tree, ground, 
235 other, NA) were recorded. We also measured distance to the closest potential 236 refuge (tree, bush, post, or fence), that is at least two meters high, from the

237 initial location of the bird. Lastly, density of trees was calculated as the number 238 of trees (defined as upright single-stemmed plants that are at least two meters 239 high) in a $15 \mathrm{~m}$ radius to account for possible habitat effects.

\subsection{FID-phi}

241 Instead of ordinary flight initiation distance (FID), we used FID-phi [note to the

242 Editor: we would like "phi" to be replaced with the corresponding Greek letter in

243 the final version. PDF conversion at the submission site was unable to display

244 the proper symbol.] that was calculated as the distance approached by the 245 observer in relation to starting distance at the moment the focal bird began escaping. The exact equation of FID-phi was: 1 - (distance approached /

247 starting distance). The use of phi index was inspired by Samia \& Blumstein 248 (2014), who used it to study the relationship between alert distance and FID, but 249 we modified the equation so that the values can be interpreted similarly to 250 ordinary FID, with larger values indicating an earlier escape. The use of a relative measure was necessary because approach type "chase" did not allow

252 us to directly measure the remaining distance to the bird (and we could not 253 simply subtract the walked distance from starting distance because the birds 254 often moved while foraging). However, due to the almost universal positive 255 correlation between starting distance and FID (Blumstein 2003), that may partly 256 be due to mathematical reasons (Dumont et al. 2012), relative measurement of 257 escape components may provide more informative results (e.g. Samia et al. 
258 2017) that are not biased by mathematical constraints (Samia \& Blumstein, 259 2014).

\section{$260 \quad 2.7$ Statistical methods}

261 The main hypotheses were tested with general linear mixed models using the 262 library Ime4 (Bates et al. 2015) in R version 3.5.2 (R Core Team 2018).

263 Continuous variables (escape duration, distance to refuge, density of trees, 264 change in escape angle) were $\log _{10}$-transformed to make the data conform 265 more closely to the normal distribution. The sample means from the values of 266 starting distance, FID-phi, and escape angle were subtracted to reduce 267 multicollinearity from the included interaction terms. Escape angle was scaled 268 by dividing by two times its standard deviation to put it on a similar scale of units 269 with other predictors (Gelman, 2008). The relationship between escape angle 270 and other variables could be non-linear, because angles below $90^{\circ}$ indicate an 271 escape towards the predator and over $90^{\circ}$ indicates escape away from the 272 predator, but we have too few observations below $90^{\circ}$ to convincingly model 273 such non-linearity. City district was used as a random factor in all models to 274 account for potential site and population specific variation. Function dredge from 275 the library MuMIn (Bartoñ 2017) was used to generate all combinations of 276 predictors from the global model. Using the same library, these combinations 277 were then ranked by Akaike information criterion (AIC) values and then model 278 averaging was done on a set of models where $\Delta A I C<4$. Uninformative 279 parameters were removed from the top model set according to the criteria 280 suggested by Leroux (2019). The natural average method was used for model 281 averaging. Estimates of predictors were considered to have support for an 
282 effect on the dependent variable whenever their $95 \%$ confidence intervals did 283 not overlap zero. Library emmeans (Lenth 2017) was used for pairwise 284 comparisons with Tukey's method, and for creating corresponding plots of 285 estimated marginal means. Partial residual plots were created with the library 286 visreg (Breheny \& Burchett 2017).

287 Circular statistics and figures were carried out with Oriana 4 software (Kovach 288 2011). Escape angle data were divided into twenty $18^{\circ}$ bins centered at $0^{\circ}$.

289 Escapes to the left and right side were pooled after finding no statistically 290 significant differences between the distributions of the left and right side for any 291 of the three species using Watson's $U^{2}$ tests (see Fig. A1 for initial escape 292 directions before pooling). Escape angle of $180^{\circ}$ indicates an escape straight 293 away from the human observer, while an angle of $0^{\circ}$ indicates escape towards 294 the observer.

\section{3. RESULTS}

\section{$296 \quad 3.1$ Escape strategy and refuge type}

297 During escape, more individuals changed their escape strategy from terrestrial 298 to aerial for approach type "chase" (34/43) compared with approach type "halt" $299(5 / 39)$ as indicated by the Chi-square test of independence, $X^{2}(1, N=82)=$ $30033.38, p<0.001$, and also compared with approach type "forward" (7/46), $\chi^{2}(1$, $301 \quad N=89)=33.95, p<0.001$. There was no significant difference in escape 302 strategies between approach type "halt" and "forward", $X^{2}(1, N=85)=0.1, p=$ 303 1.00. Previously listed $p$-values were adjusted with the Bonferroni correction. 304 Preference for refuge types was equally distributed among approach types 305 "halt", "forward", and "chase", $X^{2}(6, N=323)=3.58, p=0.734$, with ground 
being the most frequently used choice $(56.5 \%, 64.2 \%$, and $56.6 \%$, respectively), followed by trees $(17.6 \%, 16.5 \%$, and $21.7 \%$, respectively).

\subsection{Escape duration}

309 Escape duration was strongly positively correlated with distance fled, $r=0.79, N$ $310=301, p<0.001$ (Fig. A2). The global model for escape duration contained the 311 following predictors and their interactions (indicated by an asterisk): Approach type * Species + Approach type * Escape strategy + Approach type * FID-phi +

313 Escape angle * Species + Distance to refuge + Starting distance * Species +

314 Density of trees + Flock size. Density of trees and flock size were removed from 315 the top model set (i.e. models with $\triangle \mathrm{AIC}<4$ ) as these variables had little 316 statistical impact, were not directly related to main hypotheses, and could be 317 classified as uninformative parameters (model selection tables can be found in 318 the Electronic Supplementary Tables S1-S4) (Leroux, 2019).

319 Pairwise comparisons (using estimated marginal means from the model), 320 showed that, for all three species, escape duration for approach type "halt" was 321 significantly shorter than for approach type "chase", while there was a 322 significant difference between approach types "halt" and "forward" only for the 323 hooded crow (Fig. 3; Table 1 \& A1). Escape duration for approach type 324 "forward" was significantly shorter than for approach type "chase" for the 325 Eurasian jackdaw and the rook but not for the hooded crow (Fig. 3, Table 1). 326 Compared among all species, escape duration for approach type "chase" was 327 significantly different from approach types "halt" and "forward" for both terrestrial 328 and aerial escape strategies (Fig. 4; Table 2). Approach types "halt" and 329 "forward" did not differ significantly from each other for either escape strategy 
when analysed among all species (Fig. 4; Table 2). While aerial escape strategy, compared to terrestrial escape strategy, increased escape duration for approach types "halt" $(\beta=-0.174, \mathrm{SE}=0.051, p<0.001)$ and "forward" $(\beta=$ $333-0.125, \mathrm{SE}=0.044, p=0.005)$, it showed an opposite trend for approach type 334 "chase" $(\beta=0.100, \mathrm{SE}=0.047, p=0.035)$.

335 The interaction between escape angle and species showed that the relationship 336 between escape angle and escape duration was positive only for the rook (Fig.

337 A3; Table A1). Similarly, the relationship between starting distance and escape 338 duration was positive only for the rook (Fig. A4; Table A1). There was also a 339 significant interaction between approach type and FID-phi as the relationship between FID-phi and escape duration was positive only for approach type "halt"

341 (Fig. A5; Table A1). Distance to the closest refuge was positively correlated with 342 escape duration (Table A1). The density of nearby trees and flock size did not 343 affect escape duration (Electronic Supplementary Table S1).

\subsection{Escape angle}

345 The global model for escape angle contained the following predictors and their 346 interactions (indicated by an asterisk): FID-phi * Species + Escape strategy *

347 Species + Distance to refuge + Starting distance * Species. Multi-model

348 inference found no reliable relationships between the chosen predictors and 349 escape angle (Table A2).

350 The mean escape angles (after pooling escapes to the left and right side; see 351 Material and methods) were as follows: $123.4,95 \% \mathrm{Cl}[118.0,128.8]$ for the 352 Eurasian jackdaw (Fig. 5a), $118.1^{\circ}, 95 \% \mathrm{Cl}[111.4,124.8]$ for the hooded crow 
(Fig. 5b), and $117.9^{\circ}, 95 \% \mathrm{Cl}[111.3,124.5]$ for the rook (Fig. 5c). The distributions of the escape angles for the three species did not differ statistically from each other ( $p$-values $>0.05$ for all Watson's $U^{2}$ tests $)$.

\subsection{Change in escape angle}

357 The global model for change in escape angle during escape contained the 358 following predictors and their interactions (indicated by an asterisk): Approach type * Species + Approach type * Escape strategy + FID-phi + Escape duration

+ Starting distance * Species. Multi-model inference, coupled with pairwise comparisons of estimated marginal means, showed that the change in escape angle depended on approach type, with the change in escape angle being larger for approach type III than for approach type "halt", but a significant difference was found only for terrestrial escape strategy (Fig. 6; Table A3 \& A4).

365 Change in escape angle was positively related to escape duration (Table A3).

366 FID-phi, starting distance, and the interaction between approach type and species did not have support for a relationship with change in escape angle.

\section{DISCUSSION}

\subsection{Overview}

370 The main goal of the current study was to examine whether birds dynamically

371 adjust escape behaviour during escape according to the perceived risk of

372 predation. The most apparent finding to emerge from this study was that corvids

373 can easily differentiate between a predator (in this case, a human observer) that

374 pursues (approach type "chase") and one that immediately stops approaching

375 when the bird initiates escape (approach type "halt"), by increasing time spent

376 escaping (Fig. 3), by making larger adjustments in escape trajectory (Fig. 6), 
and by more frequently changing from terrestrial to aerial escape strategy.

378 Surprisingly, the Eurasian jackdaw and the rook did not show clear differences

379 in escape duration between approach type "halt" and approach type "forward"

380 (where the predator continues moving to the initial location of the bird but does

381 not chase it), while the hooded crow did (Fig. 3; Table 1). Another interspecific

382 difference was that the relationship between escape angle and escape duration

383 was positive only for the rook, while no clear relationship was found for the

384 other two species (Fig. A3). The relevance of DRA during escape is clearly

385 supported by the current findings, but the results also suggest that even closely

386 related species have different escape strategies or use different cues for

387 evaluating risk.

\subsection{Indicators of dynamic risk assessment}

389 Studies have shown that, when a stationary prey is being approached by a 390 predator, the prey will assess the costs related to fleeing and not fleeing to 391 decide on the optimal distance at which to escape (Stankowich \& Blumstein 392 2005; Cooper 2006a). However, very little is known about cost assessment 393 during escape. Before the present study, research on birds suggested that birds 394 either maximize distance from the predator by escaping at $180^{\circ}$, or escape at $39590^{\circ}$ for rapid evasion (Domenici et al. 2011). These peaks do not give an 396 impression that monitoring predators is important to birds during escape. In our 397 study, all three species had an average initial escape angle close to $120^{\circ}$ with 398 no distinctive peaks (Fig. 5), which most likely represents a middle ground 399 between maximizing distance, being unpredictable, and monitoring the predator 400 (Hall et al. 1986; Domenici \& Blake 1993). 
401 Several other results also suggest that corvids keep an eye on the actions of

402 the predator even after initiating escape. Most importantly, escape duration

403 increased when the intentions of the predator became more threatening (Fig. 3).

404 These results reflected those of Cooper (2006b) and Collier \& Hogdson (2017),

405 who found that distance fled increases in grasshoppers when the approaching

406 human is more persistent. While the choice to use terrestrial escape strategy

407 usually indicates a two to five times shorter distance fled in birds (Rodriguez-

408 Prieto et al. 2008a; Tätte et al. 2018), our study shows that this is not always

409 the case: escape duration was the longest for birds that used terrestrial escape

410 when being followed (Fig. 4a). Yet, escape duration differed between approach

411 types independently of escape strategy (Table 2), meaning that even flying

412 individuals are likely to monitor predators to make necessary changes to

413 escape duration. However, only birds using terrestrial escape showed a

414 significant increase in the angular change when being chased, after controlling

415 for escape duration that was a significant predictor of angular change (Fig. 6a;

416 Table A3). A similar, albeit not significant trend was visible for aerial escape as

417 well (Fig. 6b), although it seems that manipulating escape trajectory is more

418 important during terrestrial escape. The latter is expected, considering that

419 terrestrial escape was slower (Fig. A2). In general, prey are usually slower than

420 predators because of their smaller size, but make up for it by having smaller

421 turning radii and higher turning rates (Domenici \& Ruxton 2015).

4224.3 Escape duration in relation to escape angle

423 Escape duration was also related to initial escape angle but only for the rook.

424 Contrary to our expectations, the rook showed an increase in escape duration 
425 when escaping at more obtuse angles (Fig. A3). We initially expected that

426 escape angles away from the predator would decrease the time needed to

427 reach a safe distance. However, a possible explanation is that the rook, when

428 sensing low risk of predation, makes a short evasive manoeuvre to the side with

429 the option to continue monitoring the predator, but, when sensing a high risk of

430 predation, chooses to quickly maximize the distance. The lack of the described

431 relationship in the Eurasian jackdaw and the hooded crow could be due to a

432 more relaxed attitude towards humans, as indicated by shorter FID (Livezey et

433 al. 2016) and shorter escape durations (this study). A possible explanation, for

434 why the rook is more cautious, is that its preferred foraging technique is deep

435 probing, rather than surface picking as in the other two species (Waite, 1984).

436 Deep probing probably requires more attention on the ground that can

437 negatively affect antipredator vigilance (Lima \& Bednekoff 1999). Still, a quick

438 maximization of the distance from a human could be an unpopular option in

439 highly urbanized birds. A further study comparing urban-rural differences in that

440 matter could help to validate that hypothesis.

4414.4 Escape duration in relation to FID and starting distance

442 Escape duration was longer for earlier escapes (as measured by FID-phi, the

443 distance approached in relation to starting distance) but only for approach type

444 "halt" (Fig. A5). This result is in accordance with a previous study examining the

445 relationship between FID and distance fled (Tätte et al. 2018). A most likely

446 explanation for the lack of a similar relationship for approach type "chase" is that

447 even bold prey need to spend time on escape when being chased. The lack of a

448 relationship between FID-phi and angular change during fleeing could be an 
449 indication that late escapes did not suffer from worse initial escape angles. As a

450 reminder, escape duration was the longest for birds trying to escape terrestrially

451 when being chased, but the shortest when the predator stops (Fig. 4).

452 Therefore, it could be that boldness is an effective way to reduce costs of

453 escape if the predator is unwilling to pursue prey, although otherwise, boldness

454 can be costly. For example, Namibian rock agamas (Agama planiceps) with

455 consistently shorter FIDs, i.e. a bolder personality type, spent more time basking, eating and moving around than shyer individuals, but at the same time

457 suffered higher rates of tail loss - an indication of higher predation risk (Carter 458 et al. 2010).

459 An interesting side-result was that starting distance, i.e. the distance at which 460 the observer started his approach, was in a positive relationship with escape 461 duration for the rook but not for the other two species (Fig. A4). While the 462 positive - and variously interpreted - relationship between starting distance and 463 FID is frequently shown in numerous taxa (Blumstein 2003), a relationship 464 between starting distance and distance fled has not been found (e.g. Tätte et al. 465 2018; Kalb et al. 2019). The latter is not surprising if it is a species-specific trait 466 as seen in our study. We do not know the exact reason for why only the rook 467 increased escape duration when approached at a longer starting distance, but it 468 could once again be related to wariness of the species (as discussed in chapter 469 4.3). For example, Tätte et al. (2018) hypothesized that the relationship 470 between starting distance and FID was positive in rural but not in urban habitat 471 because urban birds need to lower their zone of awareness for not to be 
472 distracted too frequently. Starting distance did not relate to the choice of escape

473 angle or angular change during escape.

\section{$474 \quad 4.5$ Difference in the perception of approach types}

475 The finding, that at least the hooded crow perceives approach type "forward"

476 more threatening than approach type "halt" (Fig. 3; Table 1) has implications for

477 future studies of escape behaviour. Researchers need to acknowledge that

478 there could be a difference between approach type "halt" and "forward" when

479 conducting their studies. Most certainly, studies using type "halt" and "chase"

480 intermittently (e.g. Collier \& Hogdson 2017) are in danger of producing skewed

481 results. Whenever distance fled, escape duration, or hiding time are to be

482 measured, one needs to decide beforehand which approach to choose in order

483 to have all measurements taken under similar perceived risk of predation. It is

484 up to debate whether the hooded crow, being able to differentiate between

485 approach types "halt" and "forward", is better at DRA than the other two

486 species, or whether it more often incorrectly translates continued approach as

487 pursuit. After all, a predator that continues to move along the same trajectory

488 while prey escapes in another direction could be an indication that it was not

489 interested in the prey to begin with. However, making detailed assessment

490 about the trajectory of the predator in mid-flight is probably not an easy task,

491 which is why some species could rely on simple cues, i.e. whether the predator

492 stops or not. Furthermore, we noticed that sometimes birds terminate escape,

493 only to continue escaping just moments later. Such behaviour indicates that

494 even corvids are not always capable of correctly assessing risk during escape. 


\subsection{Escape angle}

496 We found no statistically reliable predictors for escape angle. That is not

497 surprising as escape trajectories usually have a high variability to provide 498 unpredictability (Domenici et al. 2011). However, since distance to closest 499 refuge was positively related to escape duration, it is possible that escape angle 500 could have been partly predictable if we had measured the angles of closest 501 refuges and added these measurements to the models (Eason et al. 2019). Still, 502 ground was the most preferred refuge type. In contrast to the study by Bateman 503 \& Fleming (2014), the preference of refuge type did not change with increasing 504 risk of predation. It is also probable that the choice of initial escape angle, 505 including vertical angle, could become more important during high-speed 506 attacks where swift evasion is required (Lind et al. 2002).

\subsection{Conclusions}

508 In general, the results of this research support the idea that birds monitor the

509 intentions of the predator while escaping to dynamically adjust their escape

510 plans. Although the study was done only on three species of corvids, it is

511 probable that similar behaviour exists in a variety of taxa because, in addition to 512 saving time and energy, prey often need to outmanoeuvre the predators that 513 chase them. In terms of studying the impact of human disturbance on wildlife, 514 the findings highlight that if one wishes to measure the true costs of escape, it 515 might be better to simulate a typical pedestrian that does not stop when prey escapes. A further study on non-urbanized animals, or using a model of some

517 other predator, could shed light on whether these behavioural patterns hold up 518 when the perceived risk of predation is considerably higher. 


\section{FUNDING}

520 This work was supported by institutional research funding IUT (34-8) of the

521 Estonian Ministry of Education and Research, and by Tartu Ülikooli Sihtasutus

522 (The Scholarship of Lydia and Felix Krabi to Kunter Tätte). 


\section{REFERENCES}

524 Bartoñ K. 2017. MuMIn: Multi-Model Inference. R package version 1.40.0. https://CRAN.R-project.org/package=MuMln

526 Bateman PW, \& Fleming PA. 2014. Switching to Plan B: changes in the escape tactics of two grasshopper species (Acrididae: Orthoptera) in response to repeated predatory approaches. Behavioral Ecology and Sociobiology, 68(3): 457-465.

Bates D, Maechler M, Bolker B, \& Walker S. 2015. Fitting Linear Mixed-Effects Models Using Ime4. Journal of Statistical Software, 67(1): 1-48. doi:10.18637/jss.v067.i01.

Breheny P, \& Burchett W. 2017. visreg: Visualization of Regression Models. R package version 2.4-1. https://CRAN.R-project.org/package=visreg

Broom M, \& Ruxton GD. 2005. You can run—or you can hide: optimal strategies for cryptic prey against pursuit predators. Behavioral Ecology, 16(3): 534-540.

Blumstein DT. 2003. Flight-initiation distance in birds is dependent on intruder starting distance. Journal of Wildlife Management, 67: 852-857.

Blumstein DT. 2006. Developing an evolutionary ecology of fear: how life history and natural history traits affect disturbance tolerance in birds. Animal Behaviour, 71(2): 389-399.

543 Carter AJ, Goldizen AW, \& Tromp SA. 2010. Agamas exhibit behavioral syndromes: bolder males bask and feed more but may suffer higher predation. Behavioral Ecology, 21(3), 655-661. 
546 Collier A, \& Hodgson JY. 2017. A Shift in Escape Strategy by Grasshopper Prey in Response to Repeated Pursuit. Southeastern Naturalist, 16(4): 503516.

549 Collop C, Stillman RA, Garbutt A, Yates MG, Rispin E, \& Yates T. 2016. Variability in the area, energy and time costs of wintering waders responding to disturbance. Ibis, 158(4): 711-725.

552 Cooper Jr WE. 1998. Direction of predator turning, a neglected cue to predation risk. Behaviour, 135(1): 55-64.

554 Cooper Jr WE. 2006a. Dynamic risk assessment: prey rapidly adjust flight 555 initiation distance to changes in predator approach speed. Ethology, 556 112(9), 858-864.

557 Cooper Jr WE. 2006b. Risk factors and escape strategy in the grasshopper 558 Dissosteira carolina. Behaviour, 143(10), 1201-1218.

559 Cooper Jr WE. 2008. Visual monitoring of predators: occurrence, cost and 560 benefit for escape. Animal Behaviour, 76(4): 1365-1372.

561 Cooper Jr WE, \& Blumstein DT (Eds.). 2015. Escaping from predators: an 562 integrative view of escape decisions. Cambridge: Cambridge University 563 Press.

564 Cooper Jr WE, Hawlena D, \& Pérez-Mellado V. 2009. Interactive effect of 565 starting distance and approach speed on escape behavior challenges theory. Behavioral Ecology, 20(3): 542-546. 
567 Cooper Jr WE, \& Pérez-Mellado V. 2004. Tradeoffs between escape behavior and foraging opportunity by the Balearic lizard (Podarcis lilfordi). Herpetologica, 60(3): 321-324.

570 Cramp S, Simmons KEL, Snow DW, \& Perrins CM. 2004. The birds of the 571 western Palearctic interactive. UK, Sheffield: BirdGuides.

572 Domenici P, Blagburn JM, \& Bacon JP. 2011. Animal escapology II: escape trajectory case studies. Journal of Experimental Biology, 214(15): 2474-

574 2494.

575 Domenici P, \& Blake R. W. 1993. Escape trajectories in angelfish (Pterophyllum 576 eimekei). Journal of Experimental Biology, 177: 253-272.

577 Domenici P, \& Ruxton GD. 2015. Prey behaviors during fleeing. In: Cooper Jr 578 WE, \& Blumstein DT (Eds.). Escaping from Predators: An Integrative 579 View of Escape Decisions. Cambridge: Cambridge University Press, pp. $113-151$.

581 Dumont F, Pasquaretta C, Réale D, Bogliani G, \& Hardenberg A. 2012. Flight 582 initiation distance and starting distance: biological effect or mathematical artefact? Ethology, 118(11): 1051-1062.

584 Eason P K, Nason LD, \& Alexander JE. 2019. Squirrels do the Math: Flight 585 Trajectories in Eastern Gray Squirrels (Sciurus carolinensis). Frontiers in 586 Ecology and Evolution, 7: 66.

587 Elts J, Kuus A, \& Leibak E. 2018. Linnuatlas. Eesti haudelindude levik ja 588 arvukus. Tartu: Estonian Ornithological Society, p. 342-349. 
589 Emery NJ, \& Clayton NS. 2004. The mentality of crows: convergent evolution of intelligence in corvids and apes. Science, 306(5703): 1903-1907.

591 Fernández-Juricic E. 2012. Sensory basis of vigilance behavior in birds: synthesis and future prospects. Behavioural Processes, 89(2): 143-152.

593 Fernández-Juricic E, O’Rourke C, \& Pitlik T. 2010. Visual coverage and 594 scanning behavior in two corvid species: American crow and Western

595 scrub jay. Journal of Comparative Physiology A, 196(12): 879-888.

Frid A, \& Dill L. 2002. Human-caused disturbance stimuli as a form of predation 597 risk. Conservation Ecology, 6(1): 11.

598 Gelman, A. 2008. Scaling regression inputs by dividing by two standard 599 deviations. Statistics In Medicine, 27(15), 2865-2873.

600 Guay PJ, Lorenz RD, Robinson RW, Symonds MR, \& Weston MA. 2013. 601 Distance from water, sex and approach direction influence flight 602 distances among habituated black swans. Ethology, 119(7), 552-558.

603 Hall SJ, Wardle CS, \& Maclennan DN. 1986. Predator evasion in a fish school: 604 Test of a model for the fountain effect. Marine Biology, 91: 143-148.

605 Hatle JD, Salazar BA, \& Whitman DW. 2001. Sluggish movement and 606 repugnant odor are positively interacting insect defensive traits in 607 encounters with frogs. Journal of Insect Behavior, 14(4): 479-496. habitat choice, rather than behavioural plasticity, is a likely driver of a 
phenotype-environment covariance. Proceedings of the Royal Society B: Biological Sciences, 284(1864), 20170943.

612 Kalb N, Anger F, \& Randler C. 2019. Flight initiation distance and escape behavior in the black redstart (Phoenicurus ochruros). Ethology, 125(7):

614 430-438.

Kovach WL. 2011. Oriana - Circular Statistics for Windows, ver. 4. Pentraeth, United Kingdom: Kovach Computing Services.

Lenth R. 2017. emmeans: Estimated Marginal Means, aka Least-Squares Means. R package version 0.9.1. https://CRAN.Rproject.org/package=emmeans

620

621

622

623

624

625

626

627

628

629

630

631

Leroux SJ. 2019. On the prevalence of uninformative parameters in statistical models applying model selection in applied ecology. PLoS One, 14(2), e0206711.

Lima SL, \& Bednekoff PA. 1999. Back to the basics of antipredatory vigilance: can nonvigilant animals detect attack? Animal Behaviour, 58(3): 537543.

Lind J, Kaby U, \& Jakobsson S. 2002. Split-second escape decisions in blue tits (Parus caeruleus). Naturwissenschaften, 89(9), 420-423.

Livezey KB, Fernández-Juricic E, \& Blumstein DT. 2016. Database of Bird Flight Initiation Distances to Assist in Estimating Effects from Human Disturbance and Delineating Buffer Areas. Journal of Fish and Wildlife Management, 7(1): 181-191. 
632 López P, \& Martín J. 2015. The personality of escape. In: Cooper Jr WE, \& Blumstein DT (Eds.). Escaping from Predators: An Integrative View of Escape Decisions. Cambridge: Cambridge University Press, pp. 385404.

636

637

638

639

640

641

642

643

644

645

646

647

648

649

650

651

652

Martin GR. 1994. Visual fields in woodcocks Scolopax rusticola (Scolopacidae; Charadriiformes). Journal of Comparative Physiology A, 174(6): 787793.

Martin GR. 2007. Visual fields and their functions in birds. Journal of Ornithology, 148(2): 547-562.

Martín J, \& López P. 2005. Wall lizards modulate refuge use through continuous assessment of predation risk level. Ethology, 111(2): 207-219.

Mikula P. 2014. Pedestrian density influences flight distances of urban birds. Ardea, 102(1), 53-61.

Møller AP. 2008. Flight distance of urban birds, predation, and selection for urban life. Behavioral Ecology and Sociobiology, 63(1), 63.

Polo-Cavia N, López P, \& Martín J. 2008. Interspecific differences in responses to predation risk may confer competitive advantages to invasive freshwater turtle species. Ethology, 114(2): 115-123.

R Core Team. 2018. R: A language and environment for statistical computing. Vienna, Austria: R Foundation for Statistical Computing. URL https://www.R-project.org/. 
653 Rodriguez-Prieto I, Fernández-Juricic E, \& Martín J. 2008a. To run or to fly: low cost versus low risk escape strategies in blackbirds. Behaviour, 145(8), $1125-1138$.

656 Rodriguez-Prieto I, Fernández-Juricic E, Martín J, \& Regis Y. 2008b. Antipredator behavior in blackbirds: habituation complements risk allocation. Behavioral Ecology, 20(2), 371-377.

Samia DS, \& Blumstein DT. 2014. Phi index: a new metric to test the flush early 660 and avoid the rush hypothesis. PLoS One, 9(11), e113134.

661 Samia DS, Blumstein DT, Díaz M, Grim T, Ibáñez-Álamo JD, Jokimäki J, Tätte 662 K, Markó G, Tryjanowski P, \& Møller AP. 2017. Rural-urban differences in escape behavior of European birds across a Latitudinal Gradient. Frontiers in Ecology and Evolution, 5: 66.

665 https://doi.org/10.3389/fevo.2017.00066.

Tätte K, Møller AP, \& Mänd R. 2018. Towards an integrated view of escape decisions in birds: relation between flight initiation distance and distance fled. Animal Behaviour, 136: 75-86.

669

Waite RK. 1984. Winter habitat selection and foraging behaviour in sympatric corvids. Ornis Scandinavica, 15: 55-62.

671 Ydenberg RC, \& Dill LM. 1986. The economics of fleeing from predators. Advances in the Study of Behavior, 16(C): 229-249. 


\section{FIGURE LEGENDS}

674 Figure 1. The graphical model by Ydenberg \& Dill (1986) predicted that when

675 the distance between a prey and an approaching predator decreases

676 (horizontal axis), cost of not fleeing (solid line) increases, while cost of fleeing

677 (dashed line) decreases, and that the intersection of these two curves would

678 predict optimal flight initiation distance $\left(D_{\text {optimal }}\right)$. The zones indicate whether risk

679 assessment takes place (zone II) or not (zone I \& III) depending on the distance

680 from the predator (Blumstein 2003). Figure is redrawn from Cooper \& Blumstein

681 (2015) with permission from Cambridge University Press.

682 Figure 2. Schematic illustration of the three approach types compared in this

683 study. $T_{1}=$ time when bird initiated escape, $t_{2}=$ time when bird stopped

684 escaping, $t_{2}-t_{1}=$ escape duration, FID $=$ flight initiation distance, $D F=$ distance

685 fled. Arrows indicate movement. Termination of approach is determined by $t_{1}$ for

686 "halt", and by $t_{2}$ for "forward" and "chase". See Material and Methods for a

687 detailed explanation.

688 Figure 3. Relationships between approach type and escape duration for (a)

689 Eurasian jackdaw, (b) hooded crow, and (c) rook. Black circles represent

690 estimated marginal means and grey rectangles represent confidence intervals

691 (both are based on predictions from a linear mixed model).

692 Figure 4. Relationships between approach type and escape duration for (a)

693 terrestrial and (b) aerial escape strategies. Black circles represent estimated

694 marginal means and grey rectangles represent confidence intervals (both are 695 based on predictions from a linear mixed model). 
696 Figure 5. Distributions of initial escape angles of (a) Eurasian jackdaw, (b)

697 hooded crow, and (c) rook. Escapes to the left and right are pooled. The human

698 observer is positioned at $0^{\circ}$ and $180^{\circ}$ indicates an escape angle directly away

699 from the human observer. Black line with error bars indicates mean escape

700 angle with $95 \%$ confidence intervals. Numbers inside the circle help to count the

701 number of escapes in different directions. Bin intervals are $18^{\circ}$.

702 Figure 6. Relationships between approach type and change in escape angle for

703 (a) terrestrial and (b) aerial escape strategies. Black circles represent estimated

704 marginal means and grey rectangles represent 95\% confidence intervals (both

705 are based on predictions from a linear mixed model).

706 
707 TABLES

708 Table 1. Pairwise comparisons of escape durations for approach types "halt",

709 "forward", and "chase" across species of birds in Estonia.

\begin{tabular}{|c|c|c|c|c|c|c|}
\hline Species & Contrast & Estimate & SE & df & $t$ & $p$ \\
\hline \multicolumn{7}{|c|}{ Eurasian jackdaw (Coloeus monedula) } \\
\hline & "halt"-"forward" & -0.025 & 0.050 & 340 & -0.50 & 0.871 \\
\hline & "halt"-“chase" & -0.280 & 0.051 & 339 & -5.50 & $<0.001$ \\
\hline & "forward"-“chase" & -0.255 & 0.052 & 338 & -4.91 & $<0.001$ \\
\hline \multicolumn{7}{|c|}{ Hooded crow (Corvus cornix) } \\
\hline & "halt"-"forward" & -0.144 & 0.059 & 346 & -2.45 & 0.039 \\
\hline & "halt"-“chase" & -0.259 & 0.062 & 340 & -4.19 & $<0.001$ \\
\hline & "forward"-"chase" & -0.115 & 0.061 & 341 & -1.89 & 0.143 \\
\hline \multicolumn{7}{|c|}{ Rook (Corvus frugilegus) } \\
\hline & "halt"-"forward" & 0.030 & 0.055 & 345 & 0.55 & 0.849 \\
\hline & "halt"-“chase" & -0.239 & 0.056 & 347 & -4.29 & $<0.001$ \\
\hline & "forward"-"chase" & -0.269 & 0.054 & 342 & -5.01 & $<0.001$ \\
\hline
\end{tabular}

710 Tukey method was used for $p$-value adjustment. Estimates in bold indicate $p$ -

711 values below significance threshold level (0.05). 
713 Table 2. Pairwise comparisons of escape durations for approach types "halt",

714 "forward", and "chase" across terrestrial and aerial escape strategies in birds in 715 Estonia.

\begin{tabular}{llllllr}
\hline $\begin{array}{l}\text { Escape } \\
\text { strategy }\end{array}$ & Contrast & Estimate & SE & df & $\boldsymbol{t}$ & $\boldsymbol{p}$ \\
\hline Terrestrial escape & & & & & & \\
& "halt"-"forward" & -0.071 & 0.051 & 347 & -1.38 & 0.351 \\
& "halt"-"chase" & $-\mathbf{0 . 3 9 6}$ & 0.053 & 346 & -7.41 & $<0.001$ \\
& "forward"-"chase" & $-\mathbf{0 . 3 2 5}$ & 0.049 & 345 & -6.64 & $<0.001$ \\
Aerial escape & & & & & & \\
& "halt"-"forward" & -0.022 & 0.040 & 340 & -0.55 & 0.848 \\
& "halt"-"chase" & $\mathbf{- 0 . 1 2 3}$ & 0.040 & 341 & -3.06 & 0.007 \\
& "forward"-"chase" & $\mathbf{- 0 . 1 0 1}$ & 0.040 & 341 & -2.51 & 0.034 \\
\hline
\end{tabular}

716 Tukey method was used for $p$-value adjustment. Estimates in bold indicate $p$ -

717 values below significance threshold level (0.05). 


\section{APPENDIX}

720 Table A1. Model averaged estimate values predicting changes in escape

721 duration of 324 birds belonging to three species. Reference levels: approach

722 type "halt", terrestrial escape for escape strategy, and Eurasian jackdaw for

723 species.

\begin{tabular}{lrrrrrr}
\hline Predictor & Estimate & $\mathbf{S E}$ & $\mathbf{2 . 5}^{\text {th }}$ & $\mathbf{9 7 . 5}^{\text {th }}$ & $\mathbf{z}$ & $\boldsymbol{w}_{\boldsymbol{i p}}$ \\
\hline (Intercept) & $\mathbf{2 . 0 9 9}$ & 0.052 & 1.996 & 2.202 & 39.97 & \\
Approach type "forward" & 0.069 & 0.058 & -0.046 & 0.183 & 1.17 & 1.00 \\
Approach type "chase" & $\mathbf{0 . 4 2 1}$ & 0.060 & 0.304 & 0.538 & 7.05 & 1.00 \\
Escape strategy & $\mathbf{0 . 1 9 1}$ & 0.053 & 0.086 & 0.295 & 3.59 & 1.00
\end{tabular}

Approach type "forward" * Escape strategy

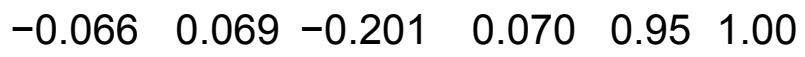

Approach type "chase" * Escape

strategy

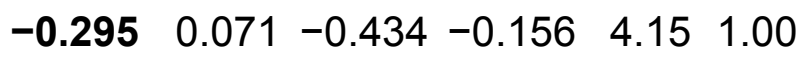

Distance to refuge

$\begin{array}{llllll}0.096 & 0.033 & 0.031 & 0.161 & 2.89 & 1.00\end{array}$

Escape angle

$\begin{array}{llllll}-0.048 & 0.041 & -0.127 & 0.032 & 1.17 & 1.00\end{array}$

Escape angle * Species (hooded crow)

$\begin{array}{llllll}0.045 & 0.063 & -0.078 & 0.169 & 0.72 & 1.00\end{array}$

Escape angle * Species (rook)

$\begin{array}{llllll}0.218 & 0.057 & 0.106 & 0.329 & 3.81 & 1.00\end{array}$

Species (hooded crow)

$\begin{array}{llllll}0.034 & 0.047 & -0.059 & 0.127 & 0.72 & 1.00\end{array}$

Species (rook)

$\begin{array}{llllll}\mathbf{0 . 2 2 9} & 0.048 & 0.134 & 0.323 & 4.74 & 1.00\end{array}$

FID-phi

$\begin{array}{llllll}0.404 & 0.202 & 0.008 & 0.801 & 2.00 & 0.78\end{array}$

$\begin{array}{lllllll}\text { Approach type "forward" * FID-phi } & \mathbf{- 0 . 5 3 4} & 0.229 & -0.983 & -0.084 & 2.33 & 0.68\end{array}$

$\begin{array}{lllllll}\text { Approach type "chase" * FID-phi } \quad-0.531 & 0.218 & -0.960 & -0.103 & 2.43 & 0.68\end{array}$

Starting distance

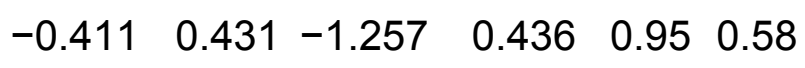

Starting distance * Species

(hooded crow)

$\begin{array}{llllll}0.047 & 0.554 & -1.043 & 1.137 & 0.09 & 0.47\end{array}$ 
Starting distance * Species (rook)

$1.109 \quad 0.526 \quad 0.073$

$2.145 \quad 2.10 \quad 0.47$

Approach type "forward" * Species

(hooded crow)

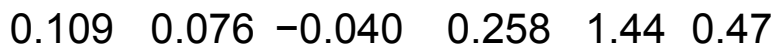

Approach type "chase" * Species

(hooded crow)

$\begin{array}{llllll}-0.039 & 0.080 & -0.196 & 0.118 & 0.49 & 0.47\end{array}$

Approach type "forward" * Species

(rook)

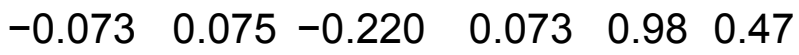

Approach type "chase" * Species

(rook)

$\begin{array}{llllll}-0.070 & 0.076 & -0.218 & 0.079 & 0.92 & 0.47\end{array}$

724 The natural average method was used for model averaging (on 13 models with

$725 \Delta \mathrm{AIC}<4$, see Electronic Supplementary Table S2). Parameter estimates are

726 followed by unconditional standard errors (SE) and $2.5^{\text {th }}$ and $97.5^{\text {th }}$ percentiles

$727(95 \% \mathrm{Cl})$. Estimates in bold indicate that $95 \% \mathrm{Cl}$ does not include $0 . W_{i p}$ is the

728 relative importance of each predictor in the model set. City district was included

729 as random effect. Some species-related effects are not showing meaningful

730 comparisons but were needed for more specific post-hoc tests. 
732 Table A2. Model averaged estimate values predicting changes in escape angle

733 of 324 birds belonging to three species. Reference levels: terrestrial escape for

734 escape strategy and Eurasian jackdaw for species.

\begin{tabular}{lrrrrrr}
\hline Predictor & Estimate & SE & $\mathbf{2 . 5}^{\text {th }}$ & $\mathbf{9 7 . 5}^{\text {th }}$ & $\boldsymbol{z}$ & $\boldsymbol{w}_{\text {ip }}$ \\
\hline (Intercept) & $\mathbf{1 . 8 3 0}$ & 0.066 & 1.701 & 1.958 & 27.85 & \\
FID-phi & $-\mathbf{0 . 5 0 6}$ & 0.190 & -0.879 & -0.133 & 2.66 & 1.00 \\
Distance to refuge & -0.093 & 0.075 & -0.240 & 0.054 & 1.24 & 0.41 \\
Escape strategy & -0.008 & 0.059 & -0.123 & 0.108 & 0.13 & 0.24 \\
Starting distance & -0.064 & 0.466 & -0.981 & 0.854 & 0.14 & 0.24 \\
Species (hooded crow) & -0.006 & 0.073 & -0.150 & 0.138 & 0.08 & 0.04 \\
Species (rook) & -0.022 & 0.069 & -0.160 & 0.115 & 0.32 & 0.04
\end{tabular}

735 The natural average method was used for model averaging (on eight models

736 with $\triangle \mathrm{AIC}<4$, see Electronic Supplementary Table S3). Parameter estimates

737 are followed by unconditional standard errors (SE) and $2.5^{\text {th }}$ and $97.5^{\text {th }}$

738 percentiles $(95 \% \mathrm{Cl}) . W_{i p}$ is the relative importance of each predictor in the

739 model set. Estimates in bold indicate that $95 \% \mathrm{Cl}$ does not include 0 . City

740 district was included as random effect. 
742 Table A3. Model averaged estimate values predicting angular change during

743 escape of 324 birds belonging to three species. Reference levels: Approach

744 type "halt" for approach type, terrestrial escape for escape strategy, and

745 Eurasian jackdaw for species.

\begin{tabular}{lrrrrrr}
\hline Predictor & Estimate & SE & $\mathbf{2 . 5}^{\text {th }}$ & $\mathbf{9 7 . 5 ^ { \text { th } }}$ & $\mathbf{z}$ & $\boldsymbol{w}_{\text {ip }}$ \\
\hline (Intercept) & $\mathbf{- 2 . 9 1 9}$ & 0.366 & -3.634 & -2.200 & 7.95 & \\
Approach type "forward" & 0.101 & 0.099 & -0.095 & 0.296 & 1.01 & 1.00 \\
Approach type "chase" & $\mathbf{0 . 3 4 2}$ & 0.116 & 0.114 & 0.571 & 2.94 & 1.00 \\
Escape duration & $\mathbf{1 . 5 4 4}$ & 0.160 & 1.229 & 1.858 & 9.63 & 1.00 \\
Escape strategy & -0.178 & $0.092-0.359$ & 0.004 & 1.91 & 0.95 \\
Species (hooded crow) & -0.162 & $0.099-0.356$ & 0.032 & 1.63 & 0.59 \\
Species (rook) & $-\mathbf{0 . 2 0 3}$ & $0.097-0.394-0.011$ & 2.07 & 0.59 \\
FID-phi & -0.303 & $0.291-0.874$ & 0.269 & 1.04 & 0.36 \\
Starting distance & 0.645 & $0.732-0.795$ & 2.084 & 0.88 & 0.34 \\
Approach type "forward" * & 0.015 & $0.188-0.354$ & 0.385 & 0.08 & 0.14 \\
Escape strategy & & & & & & \\
Approach type "chase" * Escape & -0.183 & $0.194-0.566$ & 0.200 & 0.94 & 0.14 \\
strategy & & & & & & \\
$\begin{array}{l}\text { Starting distance * Species } \\
\text { (hooded crow) }\end{array}$ & -1.173 & $1.696-4.510$ & 2.164 & 0.69 & 0.03 \\
$\begin{array}{l}\text { Starting distance * Species } \\
\text { (rook) }\end{array}$ & 0.102 & $1.625-3.094$ & 3.299 & 0.06 & 0.03 \\
\hline & & & & & & \\
\hline
\end{tabular}

746 The natural average method was used for model averaging (on 15 models with

$747 \Delta \mathrm{AIC}<4$, see Electronic Supplementary Table S4). Parameter estimates are

748 followed by unconditional standard errors (SE) and $2.5^{\text {th }}$ and $97.5^{\text {th }}$ percentiles

$749 \quad(95 \% \mathrm{Cl}) . W_{i p}$ is the relative importance of each predictor in the model set.

750 Estimates in bold indicate that $95 \% \mathrm{Cl}$ does not include 0 . City district was

751 included as random effect. 
753 Table A4. Pairwise comparisons of angular change for approach types "halt",

754 "forward", and "chase" across terrestrial and aerial escape strategies.

\begin{tabular}{|c|c|c|c|c|c|c|}
\hline $\begin{array}{l}\text { Escape } \\
\text { strategy }\end{array}$ & Contrast & Estimate & SE & df & $\boldsymbol{t}$ & $p$ \\
\hline \multicolumn{7}{|c|}{ Terrestrial escape } \\
\hline & "halt"-"forward" & -0.153 & 0.153 & 339 & -1.00 & 0.577 \\
\hline & "halt"-“chase" & -0.494 & 0.175 & 334 & -2.82 & 0.014 \\
\hline & "forward"-"chase" & -0.341 & 0.158 & 336 & -2.15 & 0.082 \\
\hline
\end{tabular}

Aerial escape

$\begin{array}{llllll}\text { "halt"-“forward" } & -0.111 & 0.119 & 334 & -0.94 & 0.619 \\ \text { "halt"-cchase" } & -0.272 & 0.121 & 332 & -2.25 & 0.065 \\ \text { "forward"-cchase" } & -0.161 & 0.123 & 334 & -1.32 & 0.388\end{array}$

755 Tukey method was used for $p$-value adjustment. Estimates in bold indicate $p$ -

756 values below significance threshold level (0.05). 
758 Figure A1. Distributions of initial escape angles of (a) Eurasian jackdaw, (b)

759 hooded crow, and (c) rook. The human observer is positioned at $0^{\circ}$, and $180^{\circ}$

760 indicates an escape angle directly away from the human observer. Numbers

761 inside the circle help to count the number of escapes in different directions. Bin

762 intervals are $18^{\circ}$.

763 Figure A2. Relationships between escape duration and linearly measured

764 distance fled by escape strategy. Blue rectangles and solid line correspond to

765 aerial escapes, red circles with dashed line correspond to terrestrial escapes,

766 and green triangles with semi-dashed line depict terrestrial escapes that

767 changed into aerial escapes midway. Model estimates (black line; linear

768 regression) are shown with 95\% confidence intervals (coloured area). Only the

769 observations that contain data on distance fled are presented.

770 Figure A3. Relationships between initial escape angle and escape duration of

771 (a) Eurasian jackdaw, (b) hooded crow, and (c) rook. Predicted model estimates

772 (black line) are shown with 95\% confidence intervals (grey area).

773 Figure A4. Relationships between starting distance and escape duration of (a)

774 Eurasian jackdaw, (b) hooded crow, and (c) rook. Predicted model estimates

775 (black line) are shown with 95\% confidence intervals (grey area).

776 Figure A5. Relationships between FID-phi and escape duration for approach

777 types (a) "halt", (b) "forward", and (c) "chase". Larger values of FID-phi indicate

778 earlier escapes. Predicted model estimates (black line) are shown with 95\%

779 confidence intervals (grey area). 
781 Overview of Electronic Supplementary Material

782 Electronic Supplementary Table S1. Initial top model set predicting escape 783 duration.

784 Electronic Supplementary Table S2. Top model set used for model averaging 785 escape duration after removing uninformative parameters.

786 Electronic Supplementary Table S3. Top model set used for model averaging 787 escape angle.

788 Electronic Supplementary Table S4. Top model set used for model averaging 789 angular change during escape. 


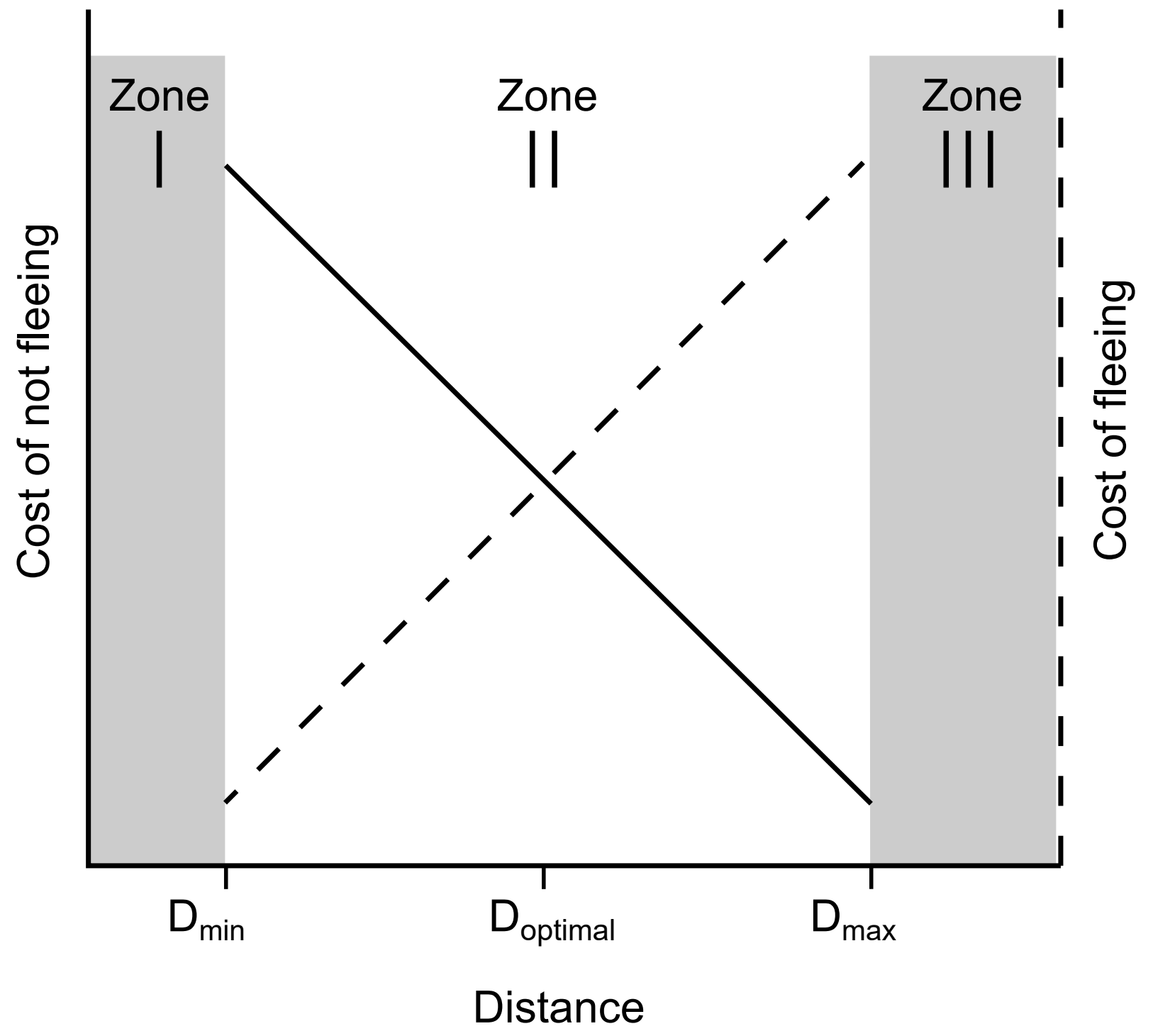




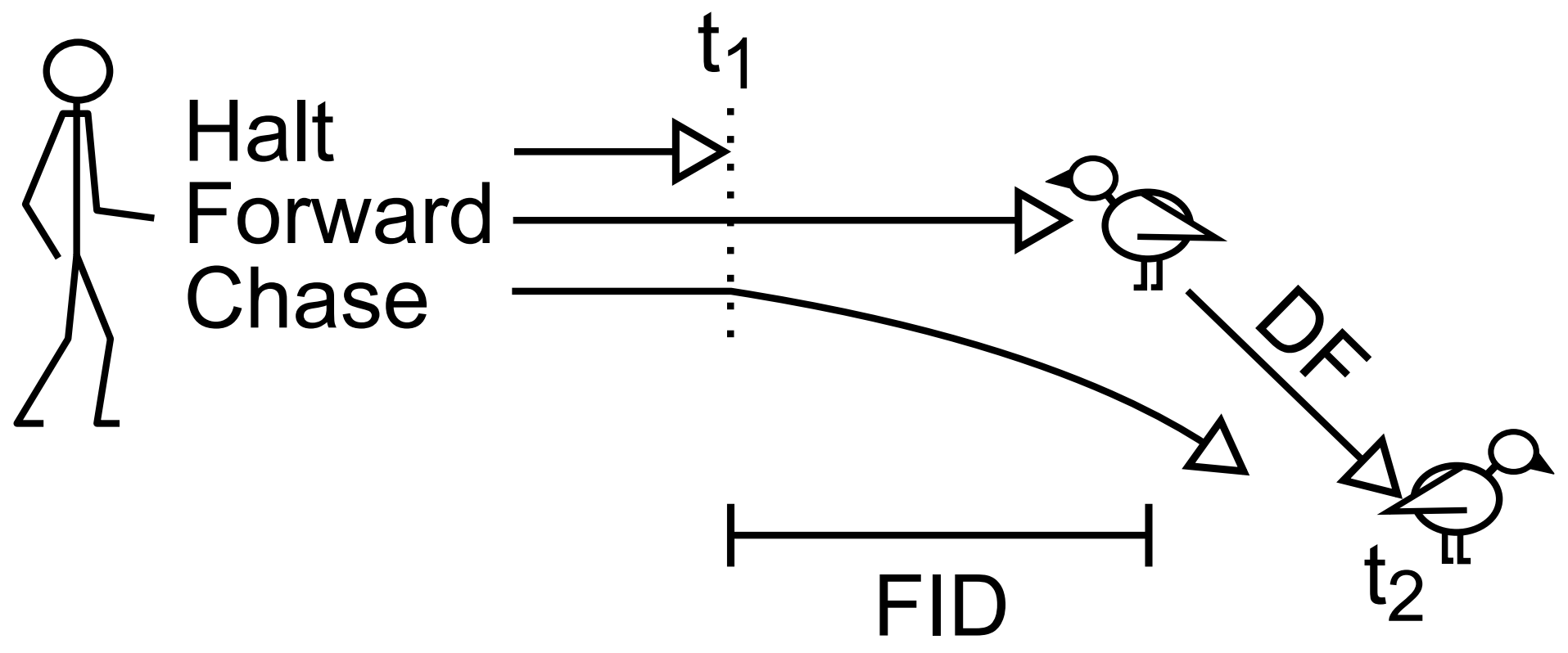



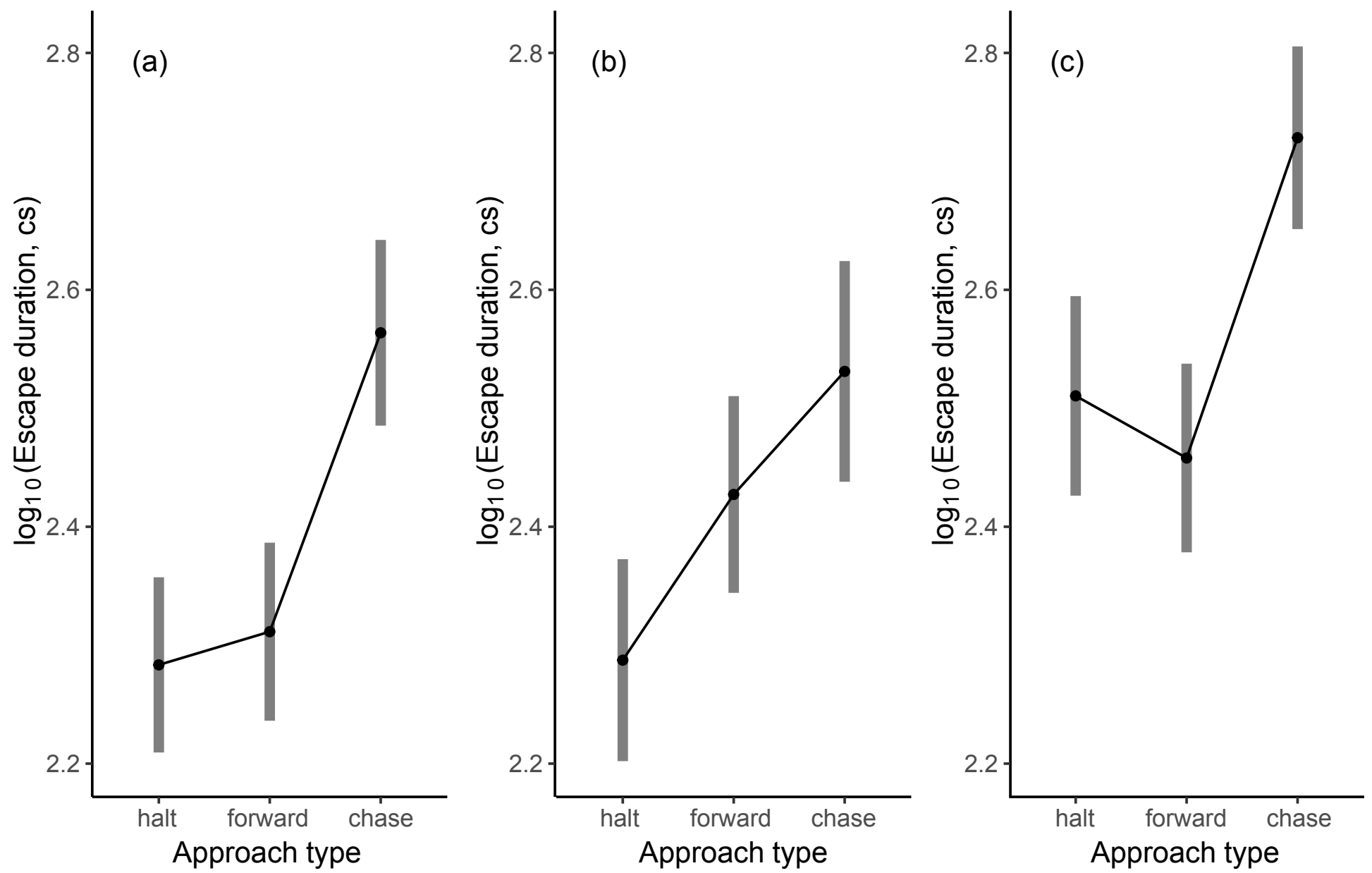

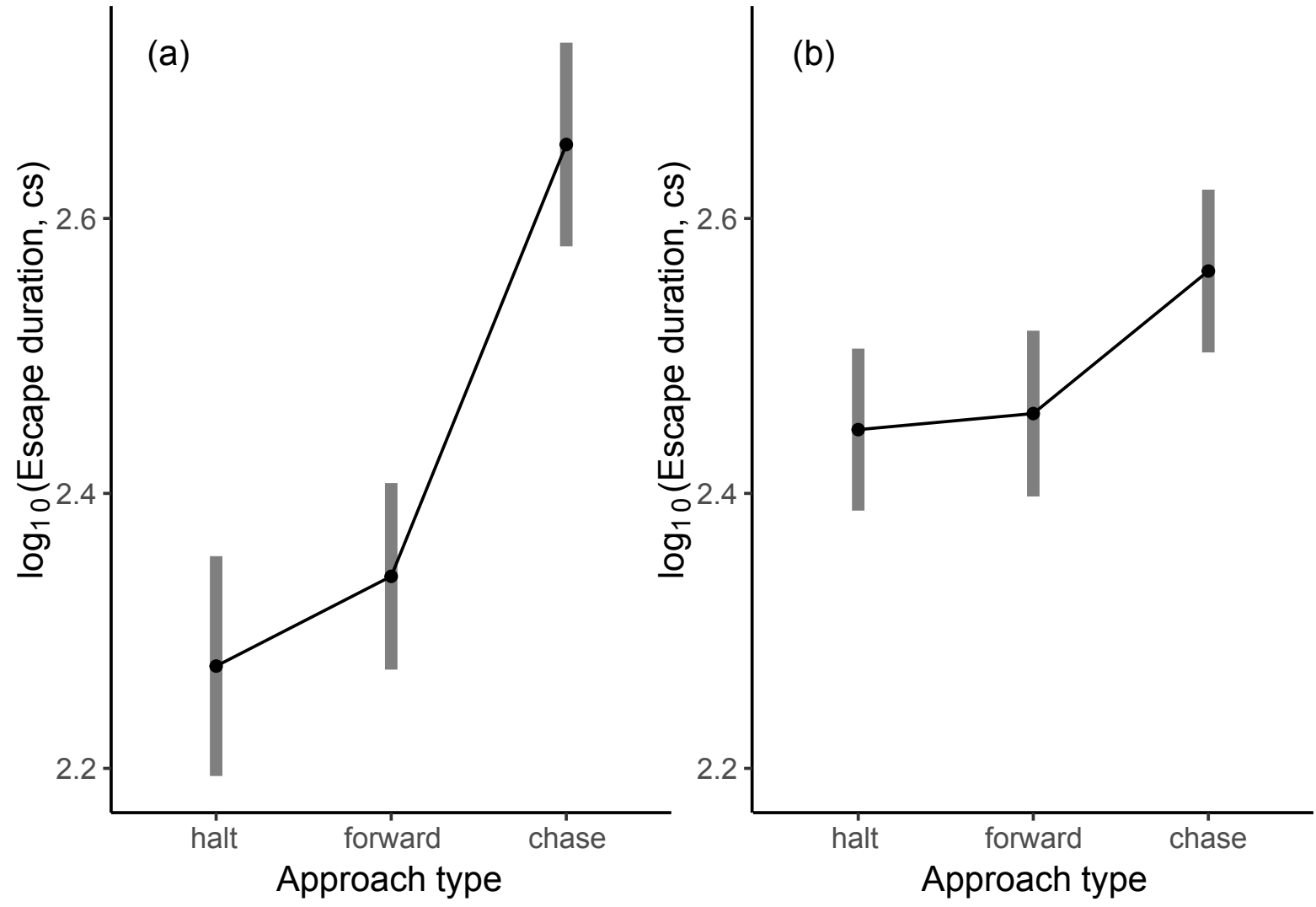
(a)

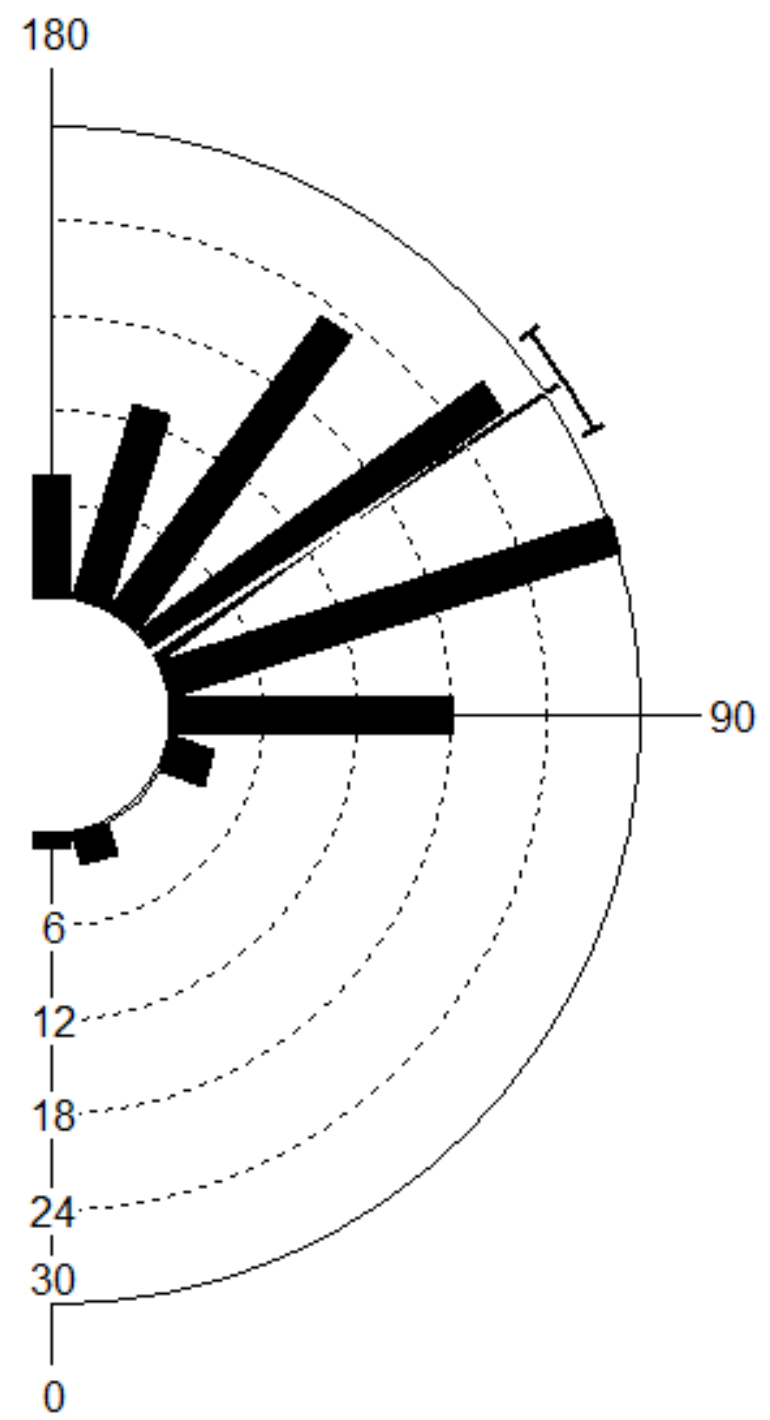

(b)

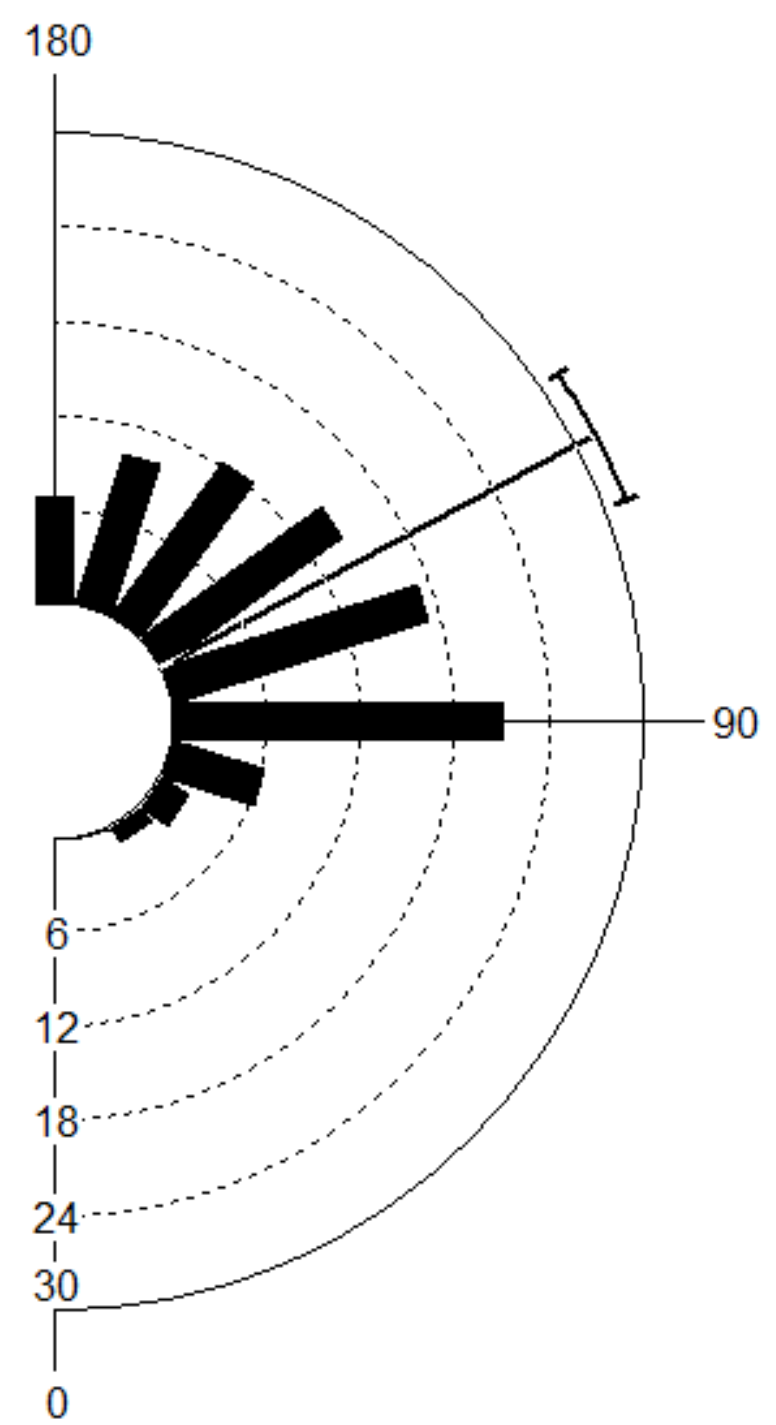

(c)

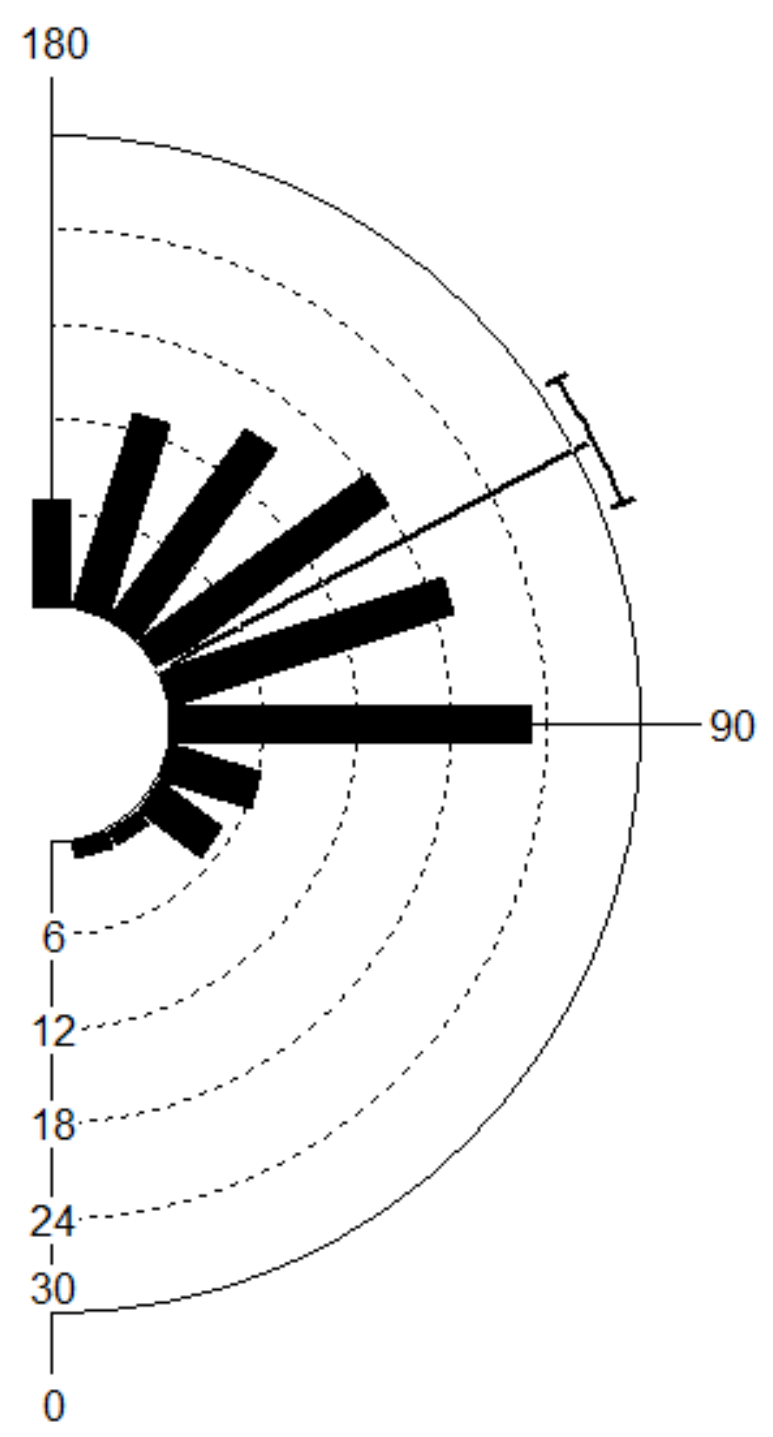



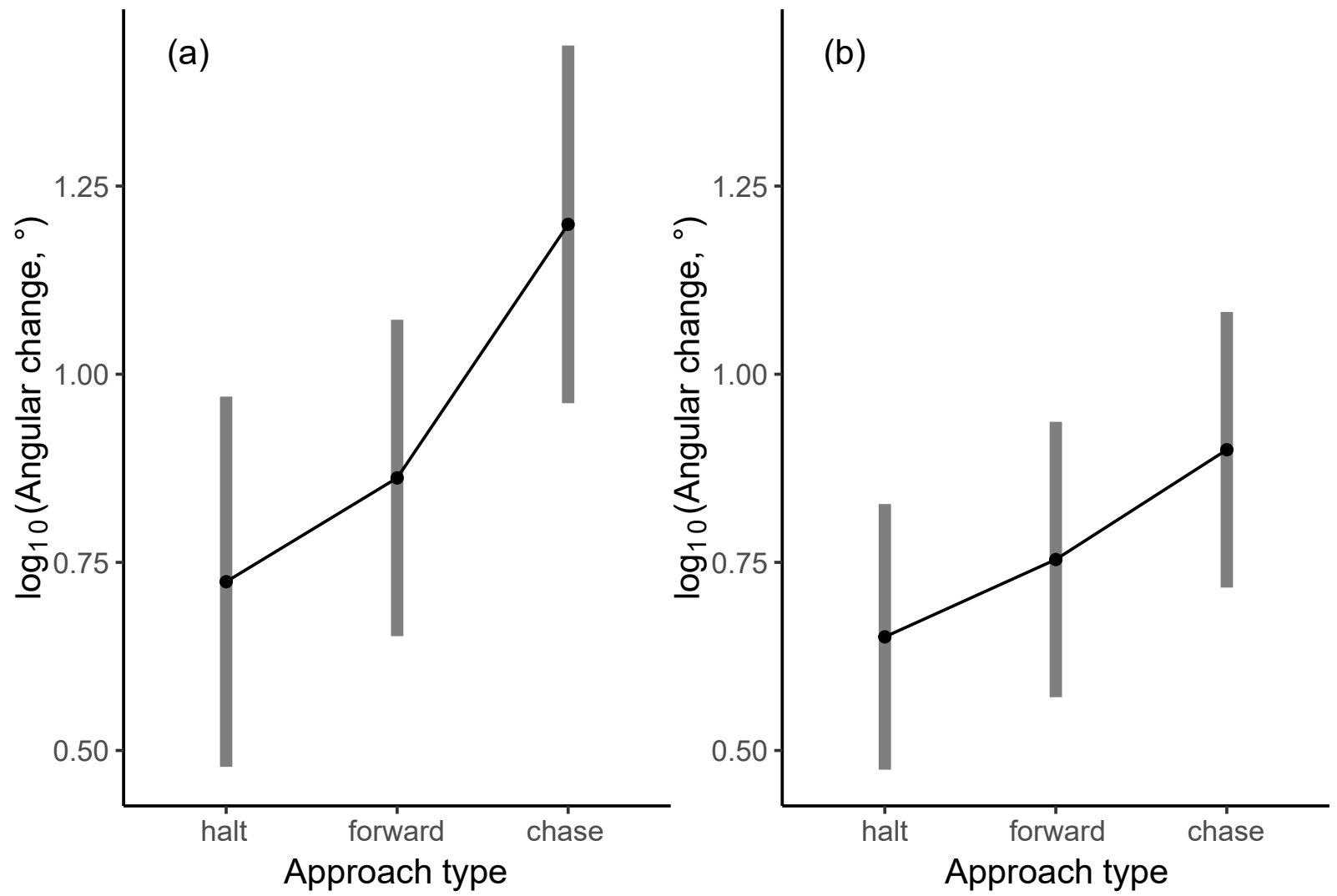

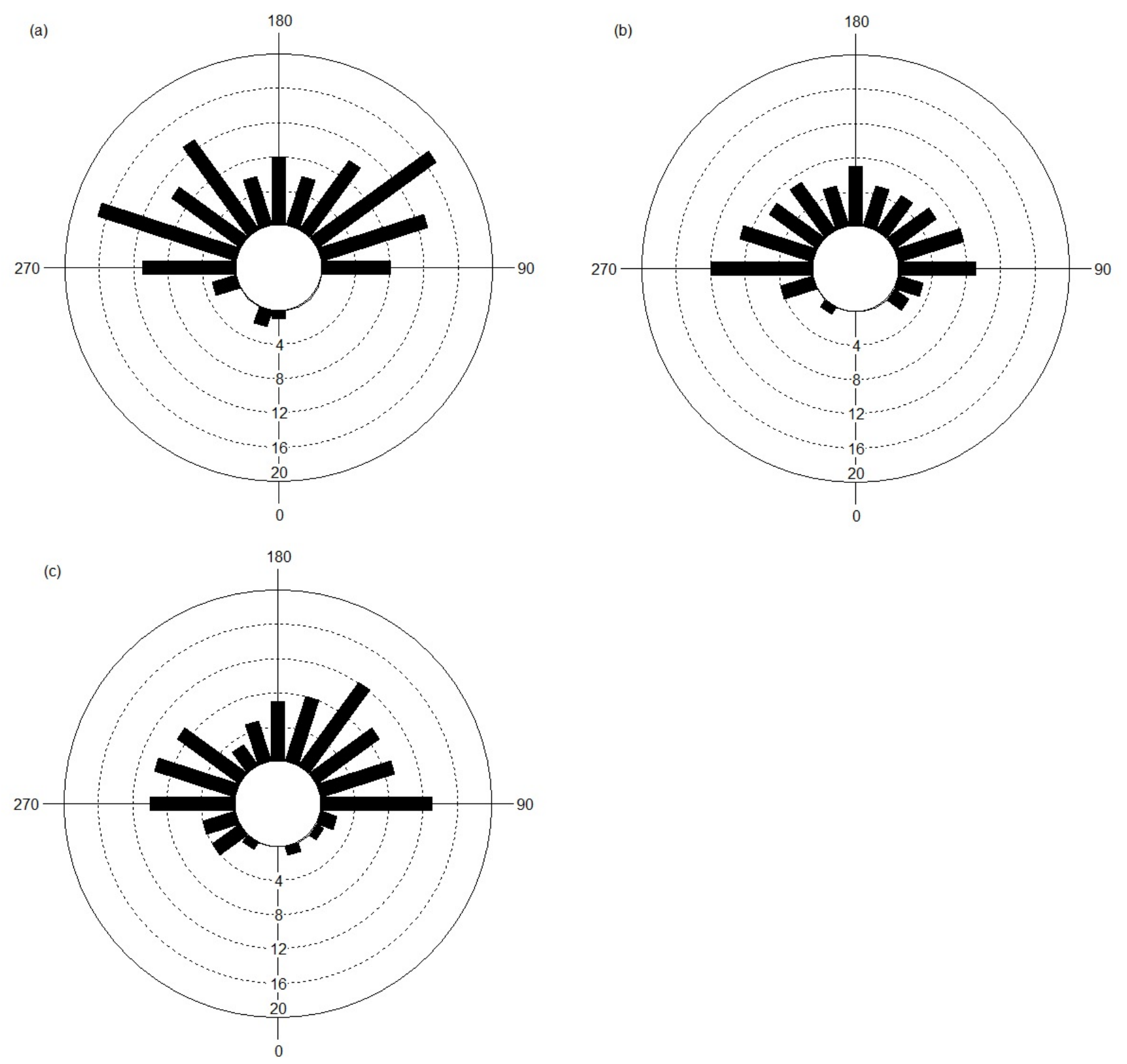


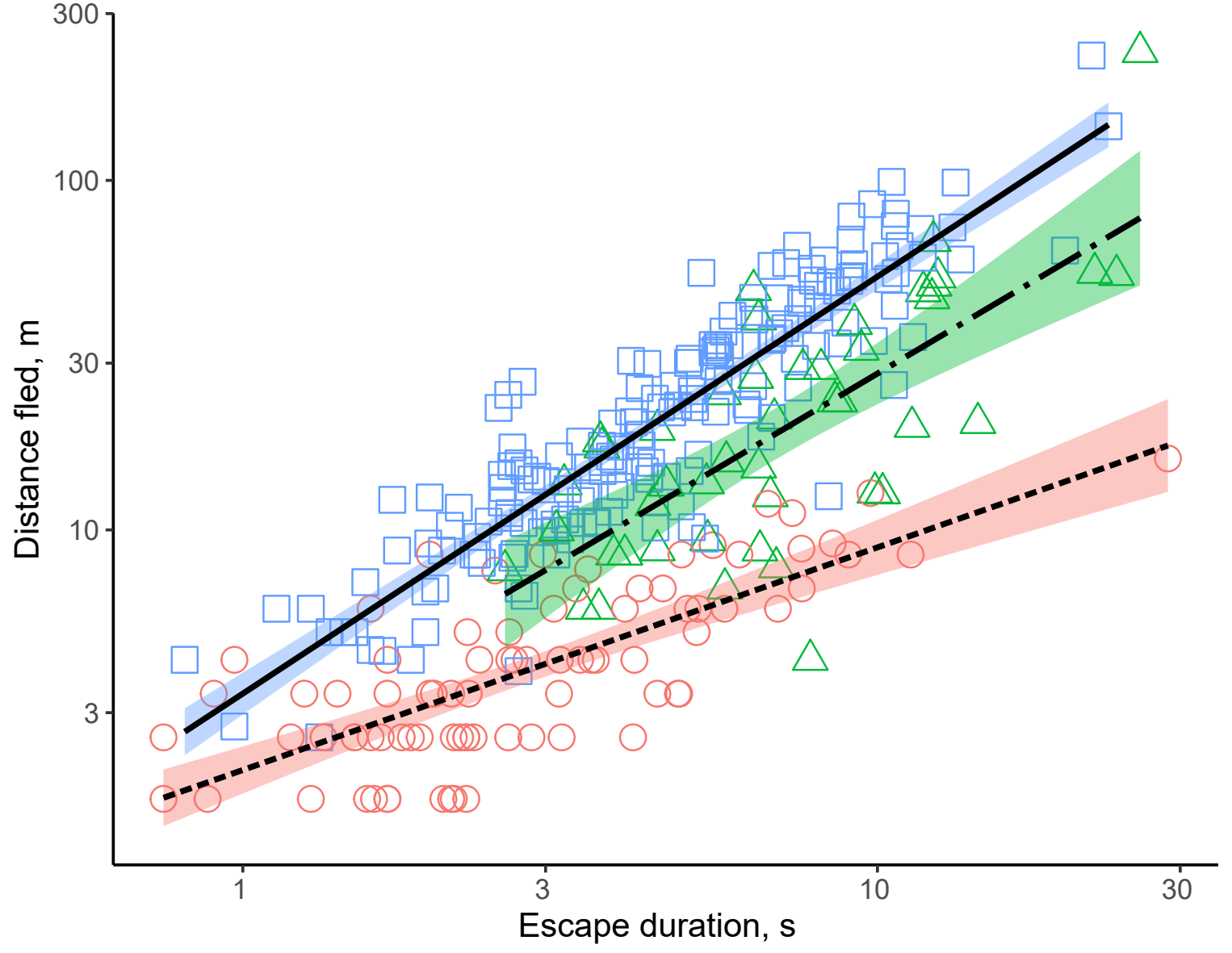




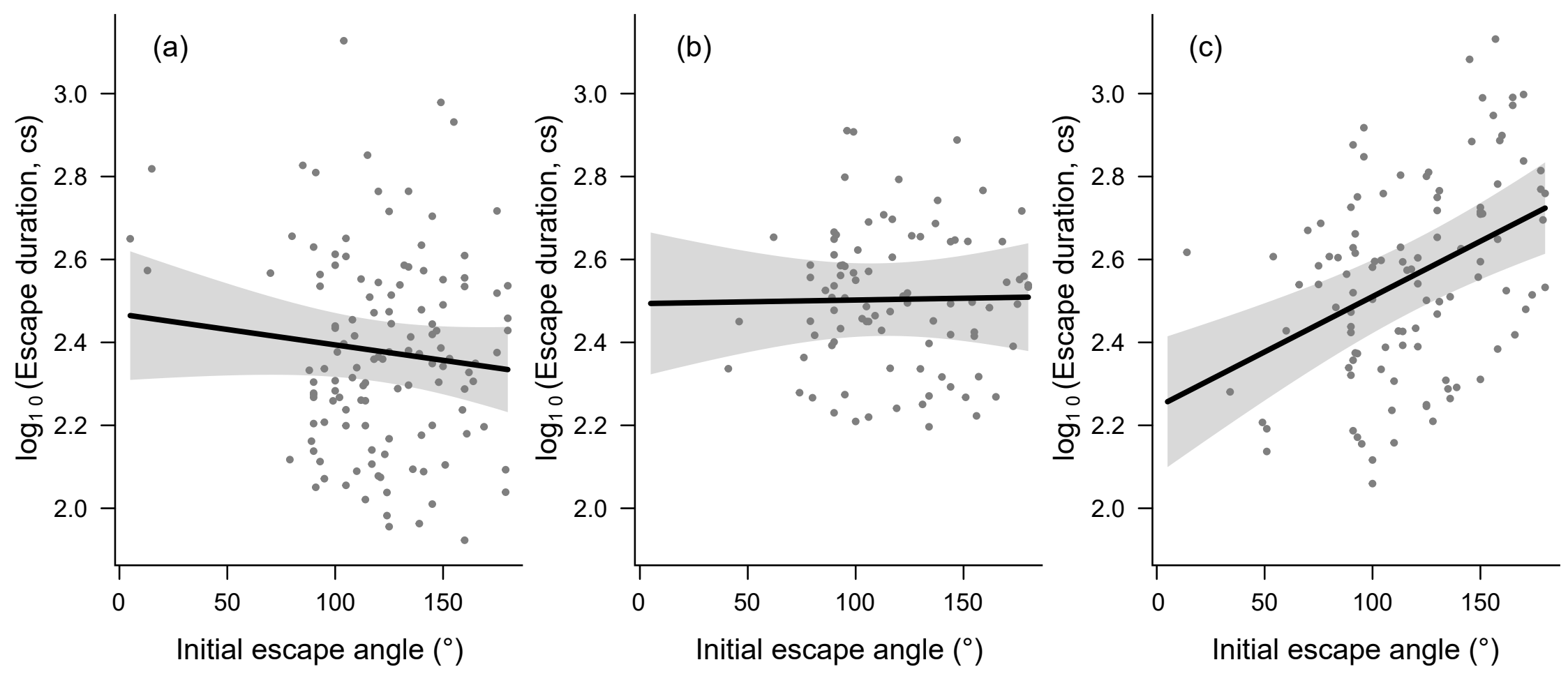



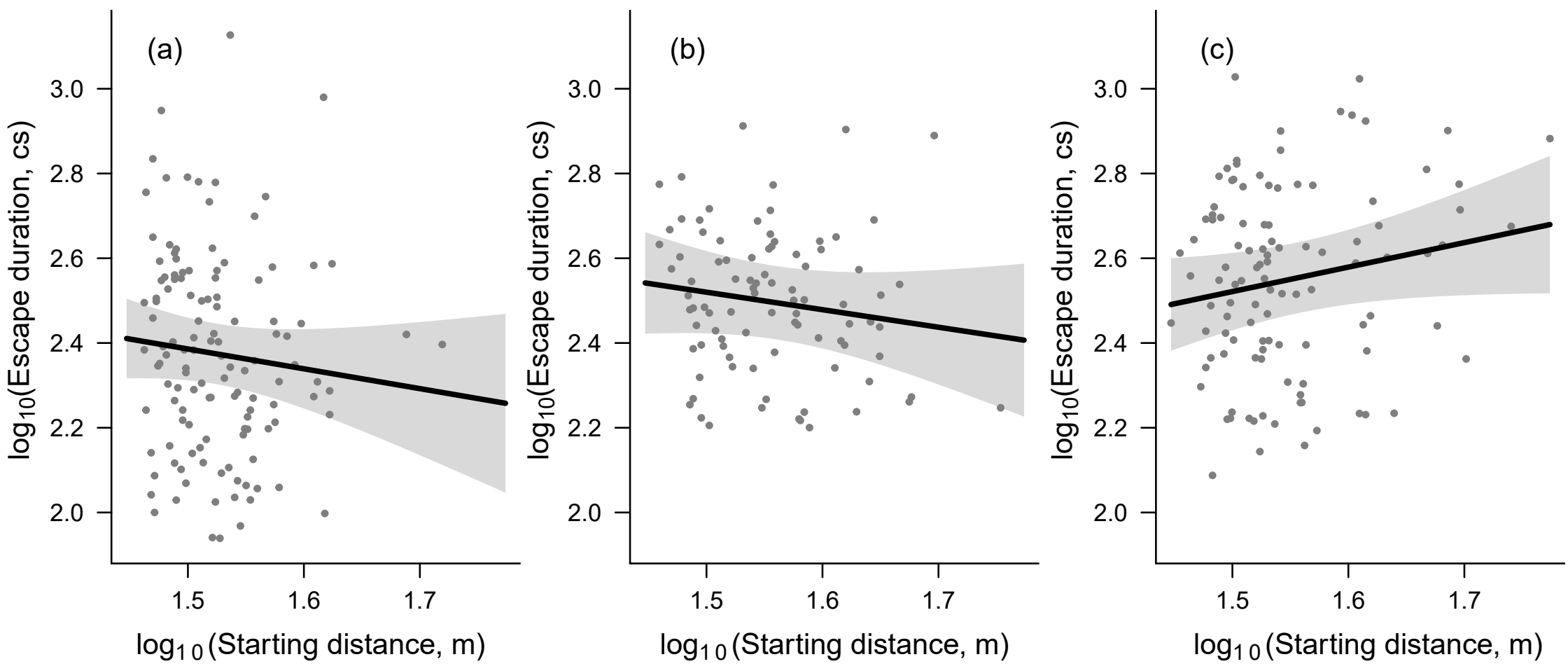

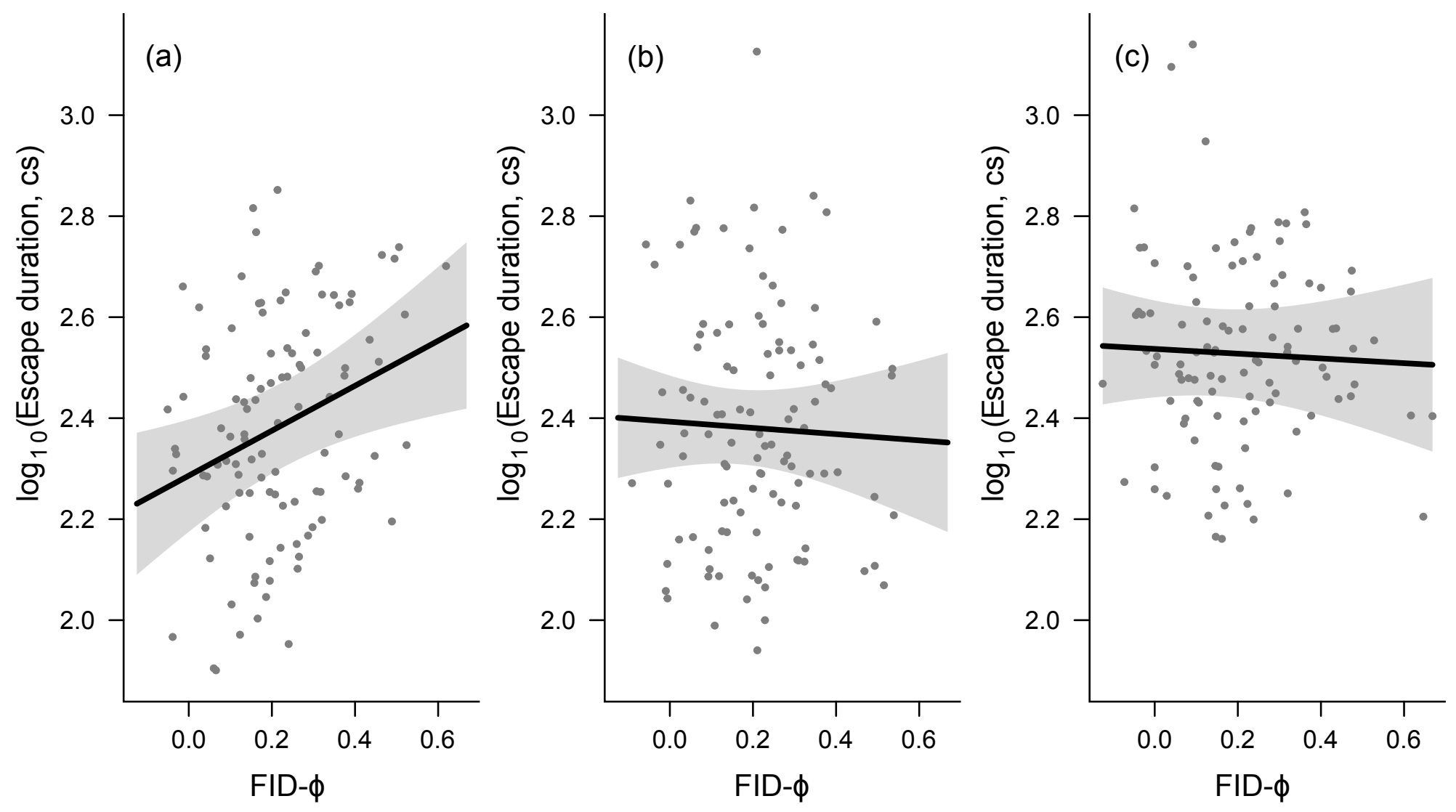


\section{AUTHOR STATEMENT}

Kunter Tätte: Conceptualization, Methodology, Investigation, Formal analysis, Writing Original Draft, Visualization Anders Pape Møller: Supervision, Writing - Review \& Editing Raivo Mänd: Supervision, Writing - Review \& Editing. 